Supporting Information for

\title{
Porous Self-Assembled Molecular Networks as Templates for Chiral Position- Controlled Chemical Functionalization of Graphitic Surfaces
}

Kazukuni Tahara, $*, 1,2,4$ Yuki Kubo, ${ }^{1}$ Shingo Hashimoto, ${ }^{2}$ Toru Ishikawa, ${ }^{1}$ Hiromasa Kaneko, ${ }^{2}$ Anton Brown, ${ }^{3}$ Brandon E. Hirsch, ${ }^{3}$ Steven De Feyter, ${ }^{* 3}$ Yoshito Tobe, ${ }^{*, 1,5,6}$

${ }^{1}$ Division of Frontier Materials Science, Graduate School of Engineering Science, Osaka University.

${ }^{2}$ Department of Applied Chemistry, School of Science and Technology, Meiji University.

${ }^{3}$ Division of Molecular Imaging and Photonics, Department of Chemistry, KU Leuven.

${ }^{4}$ PRESTO, Japan Science and Technology Agency.

5 The Institute of Scientific and Industrial Research, Osaka University.

${ }^{6}$ Department of Applied Chemistry, National Chiao Tung University.

\section{Contents}

$\begin{array}{ll}\text { 1. Experimental Details } & \text { S2 }\end{array}$

2. Molecular Modeling to Estimate Pore Size $\quad$ S4

3. Self-Assembled Monolayers Formed by DBA-OCns $(n=4$ and 8$)$ at the 1-

Phenyloctane/Graphite Interfaces

4. Templated Grafting at Double Layer Conditions Using Monolayers of DBA-OC4 and DBA-OC6 $\begin{array}{ll}\text { as Templates } & \text { S7 }\end{array}$

5. Templated Grafting at Double Layer Conditions Using Chronoamperometry (CA) S9

6. Removing Template Molecules by Washing with Hot Toluene

7. Positional Analysis on Grafted Molecular Units with Respect to Templates, DBA-OC4 and DBA-OC6

8. Analysis on Global Correspondence

9. 2D FFT Analysis of STM Image of Monolayer Formed by DBA-OC6

10. Porous Self-Assembled Monolayers Formed by cDBA-OC6(S)-OC6

11. Template Grafting at Double Layer Conditions Using TCB $\quad$ S23

12. Chirality Analysis $\quad$ S25

$\begin{array}{lr}\text { 13. Synthesis of } \mathbf{~ C D B A - O C 6}(\boldsymbol{S})-\mathbf{O C 6} & \text { S29 }\end{array}$

14. ${ }^{1} \mathrm{H}$ and ${ }^{13} \mathrm{C}$ NMR Spectra of New Compounds $\quad$ S32

$\begin{array}{ll}\text { 15. References } & \text { S35 }\end{array}$ 


\section{Experimental Details}

Chemicals. Commercially available 3,4,5-trimethoxyaniline (TCI or BLDpharm) and $\mathrm{NaNO}_{2}$ (Wako) were used as received. Hydrochloric acid (1 M) was purchased from Wako. Ultrapure water was prepared by RFU424BA/BB (ADVANTEC) or purchased from Wako. 1-Phenyloctane (TCI) and 1,2,4-trichlorobenzene (TCB, nacalai tesque) were distilled before use. Dichloromethane, hexane and acetone used for graphite washing before and after the electrochemical treatment were also purified by distillation before use. Synthesis of DBA-OCn ( $\mathrm{n}=4,6$, and 8) were reported previously. ${ }^{1-3}$ Synthesis of CDBA-OC6(S)-OC6 is summarized in section 13.

Electrochemistry. All electrochemical studies were performed using a home-built electrochemical (EC) cell and 612 DA Electrochemical Analyzer (ALS/CH instruments) or Electrochemical measurement system HZ-700 (HOKUTO DENKO). A platinum wire electrode was used as a counter electrode. The working electrode was highly-oriented pyrolytic graphite (HOPG, grade ZYB, Momentive Performance Material Quartz Inc., Strongsville, OH), and the reference electrode was a $\mathrm{Ag} / \mathrm{AgCl}$ electrode.

STM Observation. Prior to imaging of the template self-assembled molecular network (SAMN) of DBA-OCn ( $\mathrm{n}=4,6$, and 8) a compound under investigation was dissolved in 1phenyloctane. In the case of cDBA-OC6(S)-OC6, TCB was used as a solvent. Concentrations of the sample were varied in order to find optimal concentrations for the formation of porous honeycomb structures. This solution ( 30 or $40 \mu \mathrm{L}$ ) was poured to a homemade liquid cell placed on a freshly cleaved basal plane of a $1 \mathrm{~cm}^{2}$ piece of HOPG. This liquid cell was covered with a stainless lid in an oven. After annealing at $80{ }^{\circ} \mathrm{C}$ for $1 \mathrm{~h}$ (DBA-OCn) or $5 \mathrm{~h}$ (cDBA-OC6(S)-OC6), all STM observations were performed at the liquid/graphite interface at room temperature. By changing the tunneling parameters during the STM imaging, namely, the voltage applied to the substrate and the average tunneling current, it was possible to switch from the visualization of the adsorbate layer to that of the underlying HOPG substrate. This enabled us to correct for drift effects by the use of SPIP ${ }^{\mathrm{TM}}$ software (Scanning Probe Image Processor, SPIP ${ }^{\mathrm{TM}}$, version 6.1.1, ImageMetrogyA/S, Hørsholm, Denmark). White arrows and light green lines in the Figures are main symmetry axes of the graphite substrate underneath, and the in-plane directions normal to those, respectively. The unit cell parameters are determined from more than 30 experimental values of at least two calibrated STM images.

STM imaging of the functionalized surfaces after the EC treatments were also conducted at the liquid/graphite interface at room temperature (vide infra).

To determine the periodicities of the grafted species, a two-dimensional Fast Fourier Transform (2D-FFT) was applied using an extended Fourier analysis module of SPIP ${ }^{\mathrm{TM}}$ software. Only the bright parts with an apparent height higher than $150 \mathrm{pm}$ in the original STM images were 
analyzed to exclude contribution from the darker parts including the DBA cores (less than $100 \mathrm{pm}$ in height, Figure S12). To determine the hexagonal periodicities of each template network, three distances between the farthest two bright spots were measured and averaged in each 2D-FFT image. This analysis was applied for more than six large area STM images $(200 \mathrm{~nm} \times 200 \mathrm{~nm})$ to obtain mean hexagonal periodicities of the grafted species.

Raman Measurement. Raman measurements were performed in ambient condition using a NRS-3100 (JASCO) or XploRA Plus Confocal Raman Microscope (HORIBA). Laser light (532 nm, $100 \mathrm{~W}$ or $20 \mathrm{~W})$ was focused onto the sample surface from top through objective $(\times 100$ or $\times 50)$. Raman scattering was collected by the same objective and was detected by a CCD detector. For each sample, Raman spectra at more than three different positions were acquired for an excitation laser wavelength of $532 \mathrm{~nm}$. Averaged intensity ratio values of the D- and G-peaks $\left(I_{\mathrm{D}} / I_{\mathrm{G}}\right)$ are calculated from more than three spectra.

Details of Molecular Mechanics Simulations. Molecular mechanics (MM) simulations were performed with the Materials Studio 8.0 or 2017 R2 (BIOVIA) using the Forcite module with COMPASS force field. The initial structures of DBA-OC4, DBA-OC6, DBA-OC8, and cDBAOC6 $(S)$-OC6 were built from the respective molecular models which were optimized by the semiempirical PM3 method. Then the orientation of the alkyl chains relative to the $\pi$ system was adjusted based on that observed in the STM images. The molecules were placed $0.35 \mathrm{~nm}$ above the first layer of a periodic two-layer sheet of graphene with an interlayer distance of $0.335 \mathrm{~nm}$ to mimic graphite. The two-layer graphene structure was frozen during the simulations, and a cutoff of $2.0 \mathrm{~nm}$ was applied for the van der Waals interactions (Lennard-Jones type). Periodic boundary conditions (PBC) for simulations are described in Table S1.

Functionalization of Graphite at Double Layer Interface. A working electrode, HOPG was washed with dichloromethane and hexane, and the surface was cleaved using adhesive tape (Nittotape, 3800K, Nitto Denko Corporation) before use. Then, HOPG was attached to a home build EC cell. ${ }^{4,5}$ To the EC cell, 1-phenyloctane or TCB $(30$ or $40 \mu \mathrm{L})$ was added using a micropipette (P100, Gilson). After $10 \mathrm{~min}$ from the introduction of the organic liquid, a solution of 3,4,5trimethoxybenzenediazonium (TMeOD) chloride was introduced. A TMeOD solution was prepared in a sample tube by mixing a solution of 3,4,5-trimethoxyaniline $(1.0 \mathrm{mM})$ and $\mathrm{HCl}(50 \mathrm{mM})$ in water $(4.9 \mathrm{~mL})$ and a solution of $\mathrm{NaNO}_{2}$ in water $(0.10 \mathrm{M}, 100 \mu \mathrm{L})$, and by shaking the tube for $30 \mathrm{sec}$. A $500 \mu \mathrm{L}$ portion of this solution was carefully placed on the top of the 1-phenyloctane layer in the EC cell using a micropipette (P1000, Gilson), followed by addition of the remaining TMeOD solution. EC reduction was carried out using cyclic voltammetry (CV) mode in a single cycle. The timing of the initiation of the reduction was adjusted to 3 min after mixing the aniline hydrochloride and $\mathrm{NaNO}_{2}$ to maximize the concentration of TMeOD. After electrochemical reaction, the water phase was 
removed using the same micropipette, and the EC cell was carefully washed twice with ultra pure water $(5 \mathrm{~mL} \times 2)$. HOPG was removed from the EC cell, mounted in the sample holder of STM, followed by STM imaging at the liquid/HOPG interface. After imaging, the HOPG surface was dried using a hot air gun. The dried HOPG surface was analyzed by Raman spectroscopy.

Porous Network Templated Functionalization of Graphite at Double Layer Interface. All procedures for porous network templated grafting were identical to the procedure described in the previous section, except for the facts that a solution of the DBA-OC4 $\left(5.0 \times 10^{-5} \mathrm{M}\right)$, DBA-OC6 $\left(2.0 \times 10^{-5} \mathrm{M}\right)$ or DBA-OC8 $\left(6.0 \times 10^{-6} \mathrm{M}\right)$ in 1-phenyloctane $(30 \mu \mathrm{L})$ or cDBA-OC6 $(\boldsymbol{S})$-OC6 $(2.0$ $\times 10^{-5} \mathrm{M}$ ) in 1,2,4-trichlorobenzene (TCB, $\left.40 \mu \mathrm{L}\right)$ was used instead of the organic liquid (1phenyloctane or TCB) layer and the system was annealed at $80^{\circ} \mathrm{C}$ for $1 \mathrm{~h}$ (DBA-OCn) or $5 \mathrm{~h}$ (cDBAOC6(S)-OC6), and cooled down naturally to room temperature in an sealed oven, before addition of the electrolyte solution.

\section{Molecular Modeling to Estimate Pore Size}

The pore sizes formed by DBA-OCn $(n=4,6,8)$ with respect to a trimethoxyphenyl group was estimated by molecular modeling. First, honeycomb structures are optimized by MM simulations using Materials Studio 8.0 (BIOVIA) using the Forcite module with COMPASS force field with the experimentally derived unit cells as periodic boundary conditions (Table S1).

To simplify, the two long outer alkoxy chains $\left(\mathrm{OC}_{n} \mathrm{H}_{2 \mathrm{n}+2}\right)$ of DBA-OCn are replaced with methoxy groups. Then a trimethoxyphenyl unit is manually placed at the center of the pore. Resulting models indicate that the pore size is slightly too small for DBA-OC4, optimal for DBA-OC6, and slightly too large for DBA-OC8, to accommodate one trimethoxyphenyl group (Figure S1).
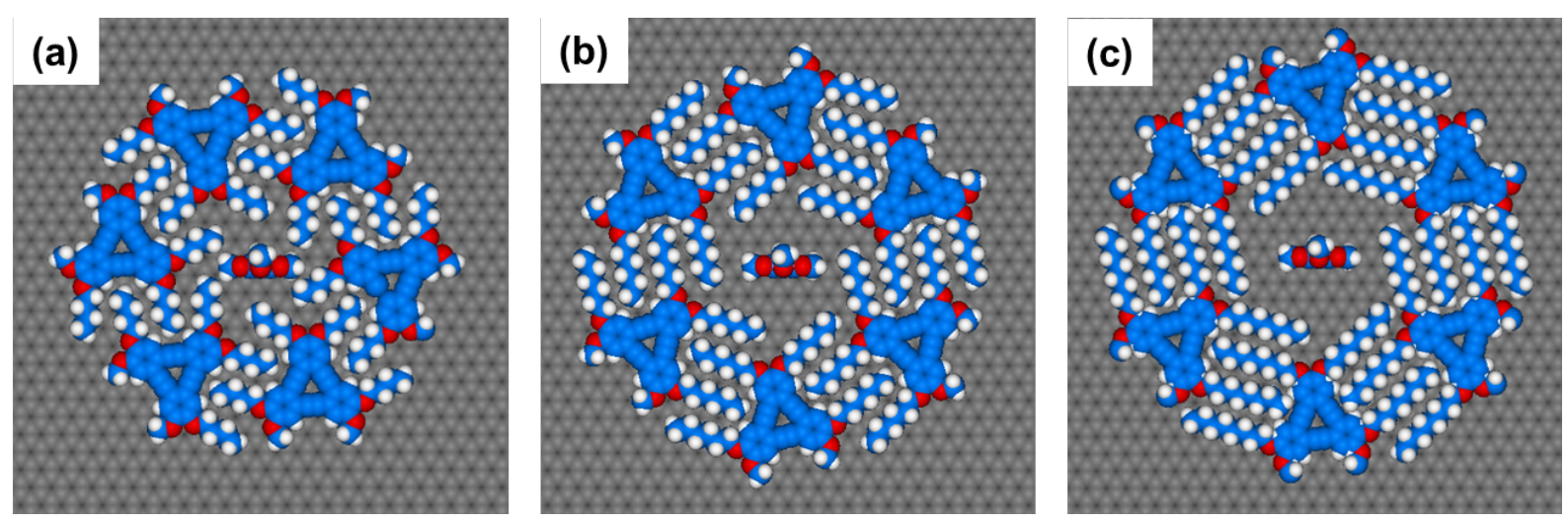

Figure S1. Models of cyclic hexamers formed by model compounds of DBA-OC4 (a), DBA-OC6 (b), and DBA-OC8 (c) on a bilayered graphene sheet, based on MM calculations. One 1,2,3trimethoxyphenyl unit is placed at the center of the pore. For each DBA molecule, the two outer alkoxy chains are replaced by methoxy groups. 
3. Self-Assembled Monolayers Formed by DBA-OCns $(n=4$ and 8$)$ at the 1Phenyloctane/Graphite Interfaces

Figures S2 displays STM images of a honeycomb structure formed by DBA-OC4 at a concentration of $5.0 \times 10^{-5} \mathrm{M}$ in 1-phenyloctane. Unit cell parameters of the honeycomb structure of DBA-OC4 are $\mathrm{a}=\mathrm{b}=2.8 \pm 0.1 \mathrm{~nm}$ and $\gamma=60 \pm 1^{\circ}$. Similarly, DBA-OC8 $\left(6.0 \times 10^{-6} \mathrm{M}\right)$ also forms extended domains of the honeycomb structure at the 1-phenyloctane/graphite interface (Figure S3). Unit cell parameters of the honeycomb structure of DBA-OC8 are $\mathrm{a}=\mathrm{b}=3.6 \pm 0.1 \mathrm{~nm}$ and $\gamma=60 \pm$ $1^{\circ}$.

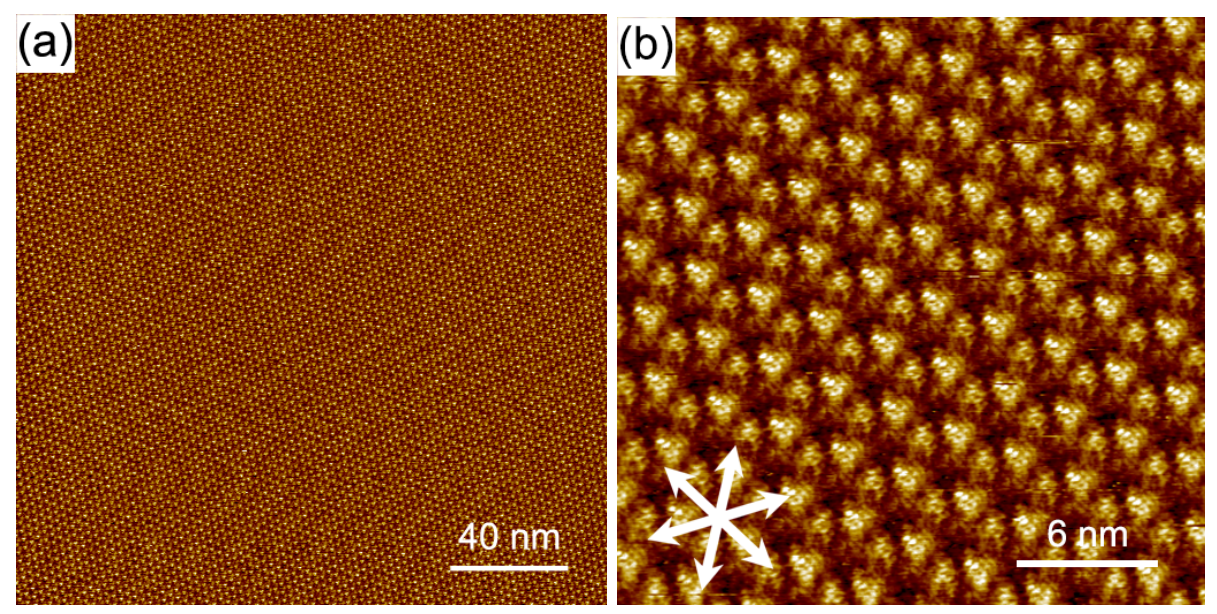

Figure S2. STM images of a SAMN of DBA-OC4 at the 1-phenyloctane/graphite interface $(5.0 \times$ $\left.10^{-5} \mathrm{M}\right)$. (a) Large area image $\left(V_{\text {bias }}=-0.50 \mathrm{~V}, I_{\text {set }}=30 \mathrm{pA}\right)$. (b) Small area image $\left(V_{\text {bias }}=-0.50 \mathrm{~V}\right.$, $I_{\text {set }}=30 \mathrm{pA}$ ). Unit cell parameters are $\mathrm{a}=\mathrm{b}=2.8 \pm 0.1 \mathrm{~nm}$ and $\gamma=60 \pm 1^{\circ}$.
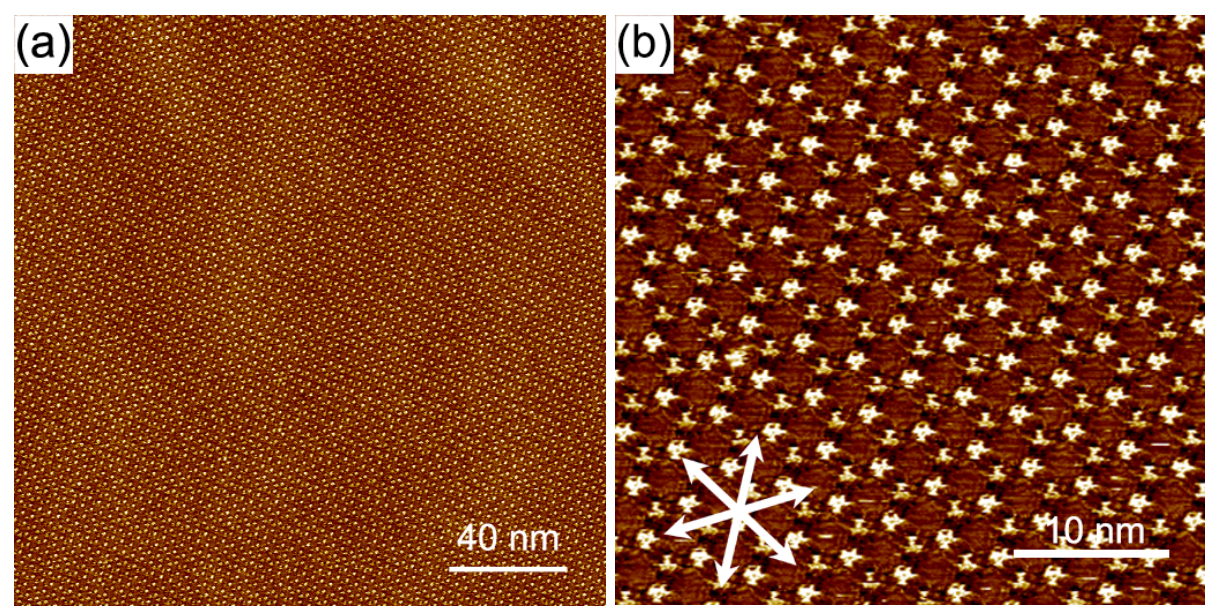

Figure S3. STM images of a SAMN of DBA-OC8 at the 1-phenyloctane/graphite interface $(6.0 \times$ $\left.10^{-6} \mathrm{M}\right)$. (a) Large area image $\left(V_{\text {bias }}=-0.60 \mathrm{~V}, I_{\text {set }}=30 \mathrm{pA}\right)$. (b) Small area image $\left(V_{\text {bias }}=-0.60 \mathrm{~V}\right.$, $I_{\text {set }}=30 \mathrm{pA}$ ). Unit cell parameters are $\mathrm{a}=\mathrm{b}=3.6 \pm 0.1 \mathrm{~nm}$ and $\gamma=60 \pm 1^{\circ}$. 
According to the STM images, honeycomb structures are optimized using MM simulations using the experimentally derived unit cell as PBC conditions. Optimized structures are displayed in Figure S4. The structural parameters are summarized in Table S1.

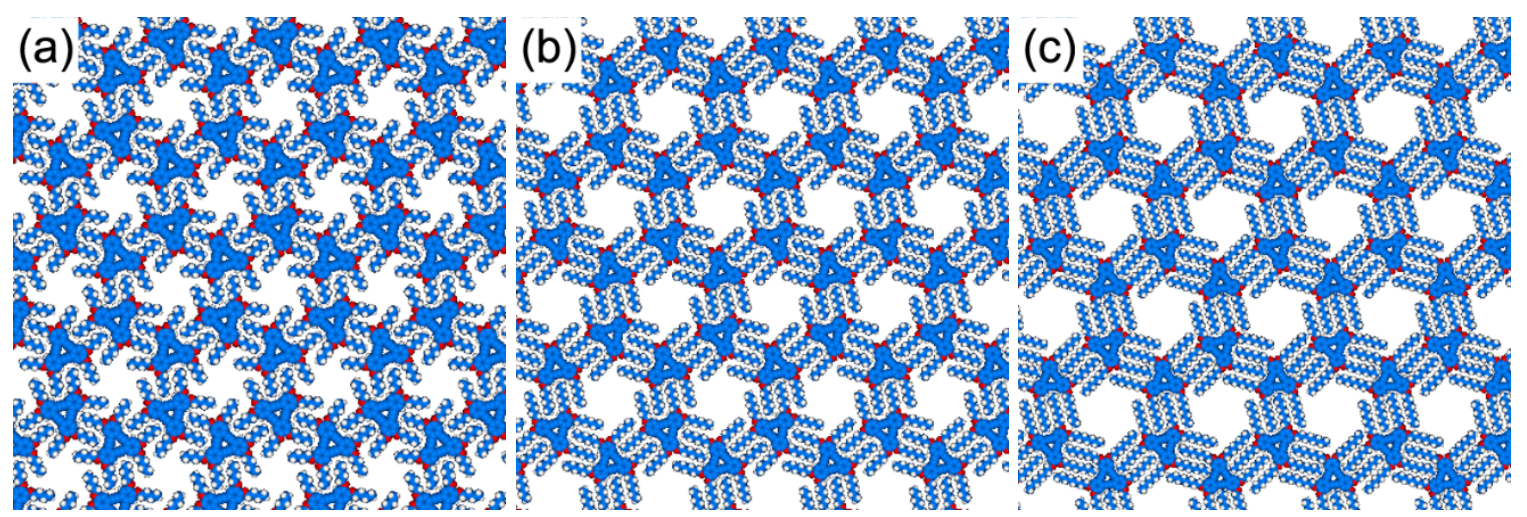

Figure S4. Molecular mechanics optimized (COMPASS force field) molecular models of the honeycomb structures of DBA-OC4, DBA-OC6, and DBA-OC8 on bilayered graphene sheets under PBCs $\left(\mathrm{a}=\mathrm{b}=2.84 \mathrm{~nm}\right.$ and $\gamma=60.0^{\circ}$ for DBA-OC4, $\mathrm{a}=\mathrm{b}=3.25 \mathrm{~nm}$ and $\gamma=60.0^{\circ}$ for DBA-OC6, and $\gamma=60.0^{\circ}, \mathrm{a}=\mathrm{b}=3.62 \mathrm{~nm}$ and $\gamma=60.0^{\circ}$ for DBA-OC8). The bilayered graphene sheets are omitted for clarity.

Table S1. Experimentally Derived Unit Cell Parameters, Periodic Boundary Conditions (PBC) Used for MM Simulations, and MM Estimated Pore Sizes.

\begin{tabular}{|c|c|c|c|}
\hline compound & $\begin{array}{c}\text { experimentally derived } \\
\text { unit cell parameters }\end{array}$ & $\begin{array}{c}\text { periodic boundary } \\
\text { conditions for MM } \\
\text { simulations }\end{array}$ & pore size $^{a}$ \\
\hline DBA-OC4 & $\mathrm{a}=\mathrm{b}=2.8 \pm 0.1 \mathrm{~nm}$ \\
$\gamma=60 \pm 1^{\circ}$ & $\mathrm{a}=\mathrm{b}=2.84 \mathrm{~nm}$ \\
$\gamma=60.0^{\circ}$ & $1.2 \mathrm{~nm}$ \\
\hline DBA-OC6 & $\mathrm{a}=\mathrm{b}=3.2 \pm 0.1 \mathrm{~nm}$ & $\mathrm{a}=\mathrm{b}=3.25 \mathrm{~nm}$ & $1.6 \mathrm{~nm}$ \\
\hline DBA-OC8 & $\mathrm{a}=\mathrm{b}=3.6 \pm 0.1 \mathrm{~nm}$ & $\mathrm{a}=\mathrm{b}=3.62 \mathrm{~nm}$ & $2.0 \mathrm{~nm}$ \\
\hline cDBA-OC6(S)- & $\mathrm{a}=\mathrm{b}=3.2 \pm 0.1 \mathrm{~nm}$ & $\mathrm{a}=\mathrm{b}=3.25 \mathrm{~nm}$ & $1.6 \mathrm{~nm}$ \\
\hline OC6 & $\gamma=60 \pm 1^{\circ}$ & $\gamma=60.0^{\circ}$ & \\
\hline
\end{tabular}

${ }^{a}$ The corner to corner interatomic distance between the terminal carbon atoms of the alkoxy chains placed at the rim of the pore. 


\section{Templated Grafting at Double Layer Conditions Using Monolayers of DBA-OC4 and DBA-}

OC6 as Templates
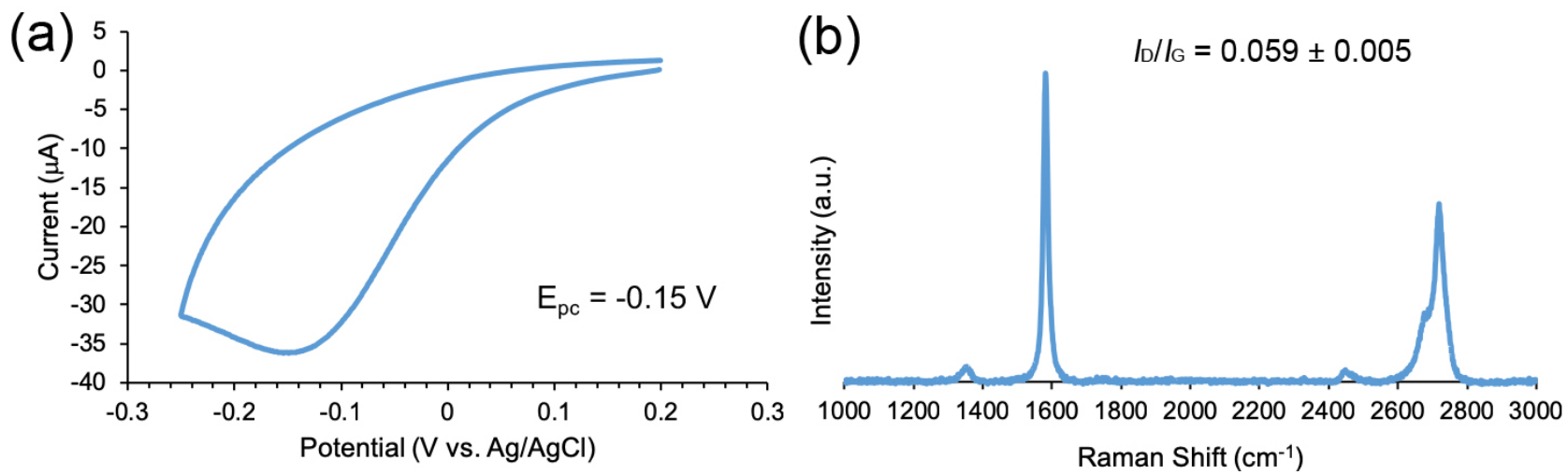

Figure S5. (a) CV inducing electrochemical grafting of TMeOD on graphite at phase separated solution double layer conditions $(+0.20$ to $-0.25 \mathrm{~V}, 0.1 \mathrm{~V} / \mathrm{sec})$ with a DBA-OC6 SAMN as template layer. 1-Phenyloctane was used as the organic solvent layer. (b) Raman spectrum after drying the surface. Mean $I_{\mathrm{D}} / I_{\mathrm{G}}$ is $0.059 \pm 0.005$.
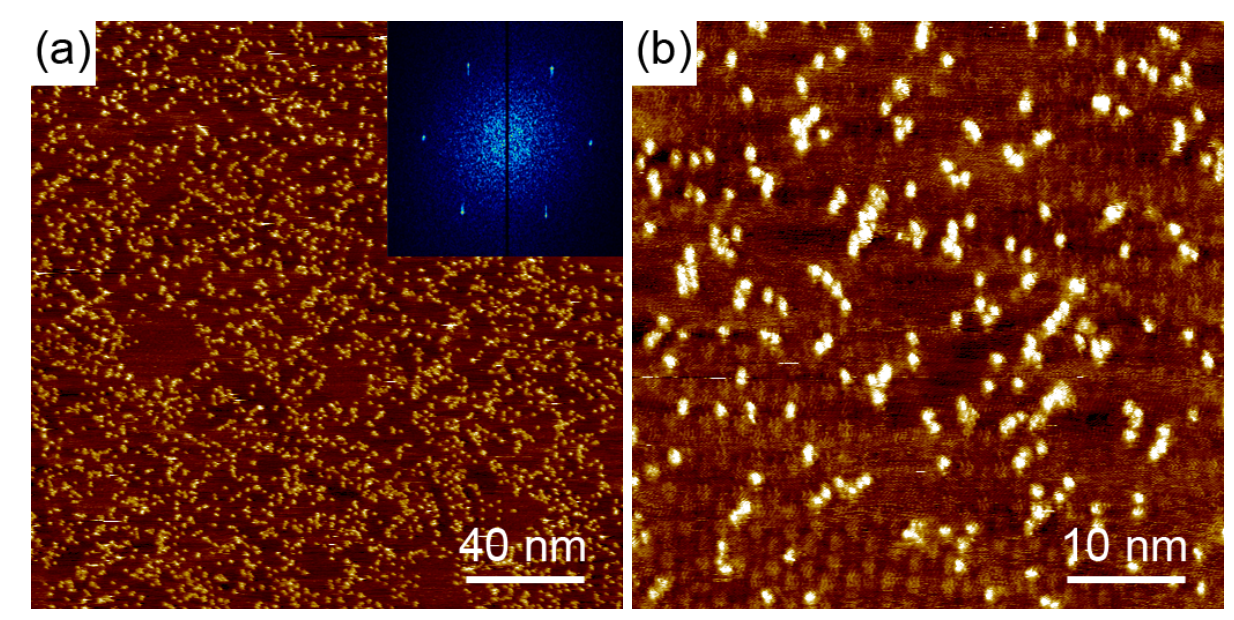

Figure S6. STM images of the functionalized graphite surface after DBA-OC6 templated grafting in 1-phenyloctane. (a) Large area image $\left(V_{\text {bias }}=-0.60 \mathrm{~V}, I_{\text {set }}=30 \mathrm{pA}\right)$. Inset: corresponding 2D-FFT image, showing 6 bright spots. (b) Small area image $\left(V_{\text {bias }}=-0.90 \mathrm{~V}, I_{\text {set }}=30 \mathrm{pA}\right)$. The bright dots are the grafted molecules. The faint bright spots are the DBA units of the SAMN template. 

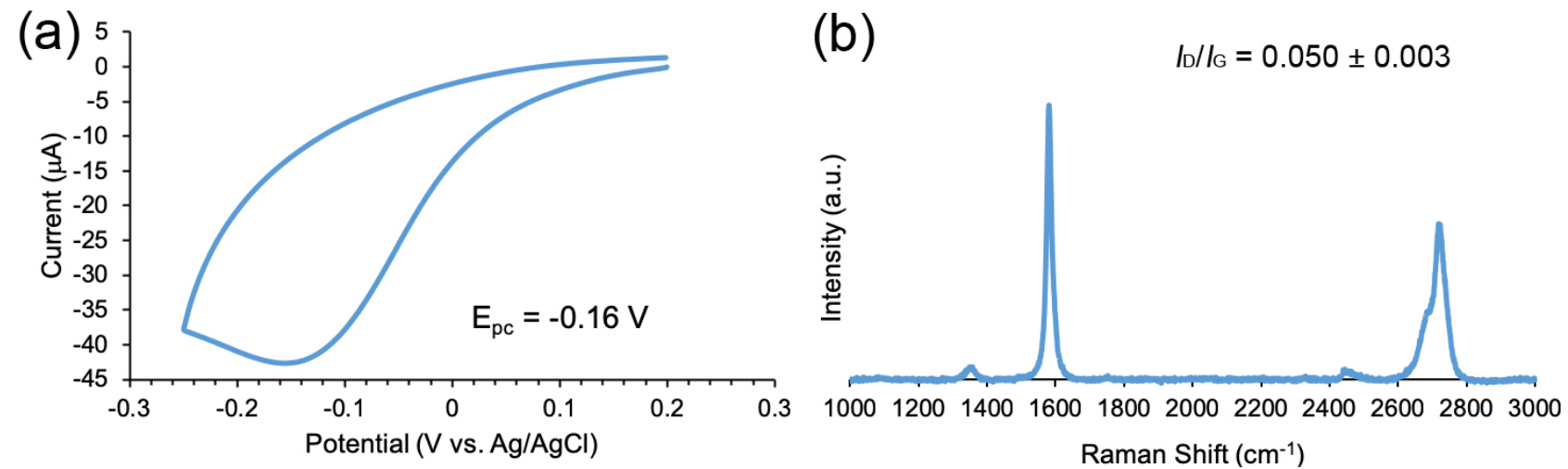

Figure S7. (a) CV inducing electrochemical grafting of TMeOD on graphite at phase separated solution double layer conditions $(+0.20$ to $-0.25 \mathrm{~V}, 0.1 \mathrm{~V} / \mathrm{sec})$ with a DBA-OC4 SAMN as template layer. 1-Phenyloctane was used as the organic solvent layer. (b) Raman spectrum after drying the surface. Mean $I_{\mathrm{D}} / I_{\mathrm{G}}$ is $0.050 \pm 0.003$.
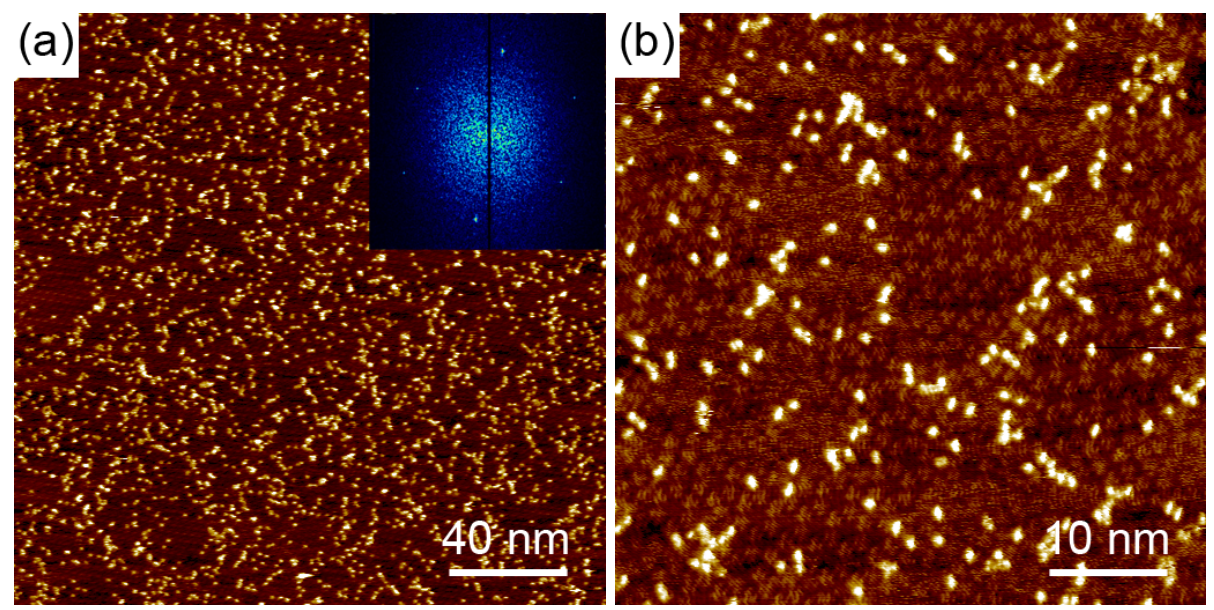

Figure S8. STM images of functionalized graphite surface after DBA-OC4 templated grafting in 1phenyloctane. (a) Large area image $\left(V_{\text {bias }}=-0.80 \mathrm{~V}, I_{\text {set }}=30 \mathrm{pA}\right)$. Inset: corresponding 2D-FFT image, showing 6 bright spots. A large dim feature appears at the center of the FFT image, indicating the contribution of randomly located trimethoxyphenyl units on the surface. (b) Small area image $\left(V_{\text {bias }}=-0.80 \mathrm{~V}, I_{\text {set }}=30 \mathrm{pA}\right)$. The bright dots are the grafted molecules. The faint bright spots are the DBA units of the SAMN template. 


\section{Templated Grafting at Double Layer Conditions Using Chronoamperometry (CA)}

To investigate whether a different electrochemical technique changes the pattern transfer fidelity or not, chronoamperometry (CA) was used instead of CV mode for the electrochemical reduction of the aryldiazonium salt. DBA-OC6 is employed as the template molecule. The aqueous solution of 3,4,5-trimethoxybenzenediazonium (TMeOD) chloride is at a concentration of $2 \mathrm{mM}$. An electrode potential at $-0.15 \mathrm{~V}$ (vs. $\mathrm{Ag} / \mathrm{AgCl}$ ) was applied for 2 seconds to reduce the aryldiazonium salt at double layer conditions (Figure S9a). After washing the surface with ultrapure water, the functionalized surface was imaged by means of STM (Figure S10). Figure S10a is a large area image of the functionalized surface. The brightest dots correspond to the grafted aryl units, and the dim features correspond to the DBA molecules. The grafted aryl units align hexagonally, which is confirmed by the 2D-FFT image shown as an inset in Figure S10a. The $I_{D} / I_{G}$ value becomes $0.058 \pm$ 0.001 (Figure S9b), which is comparable to the functionalized surface using CV. At present data, we do not have an obvious difference between CA and CV modes.
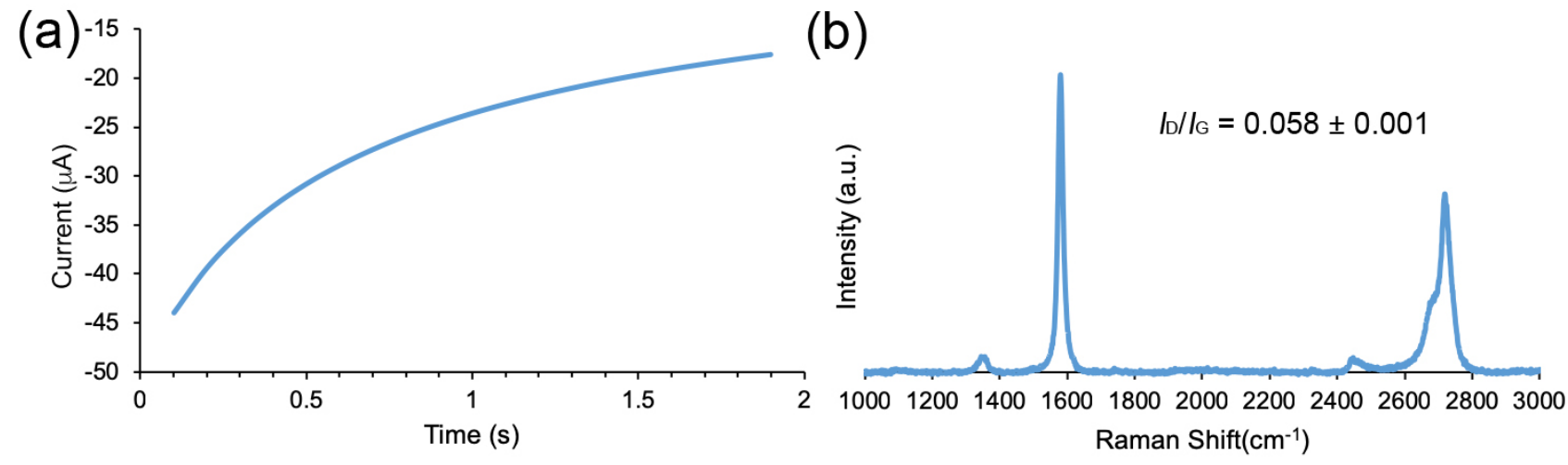

Figure S9. (a) CA inducing electrochemical grafting of TMeOD on graphite at phase separated solution double layer conditions $(-0.15 \mathrm{~V})$ with a DBA-OC6 SAMN as template layer. 1Phenyloctane was used as the organic solvent layer. (b) Raman spectrum after drying the surface. Mean $I_{\mathrm{D}} / I_{\mathrm{G}}$ is $0.058 \pm 0.001$. 

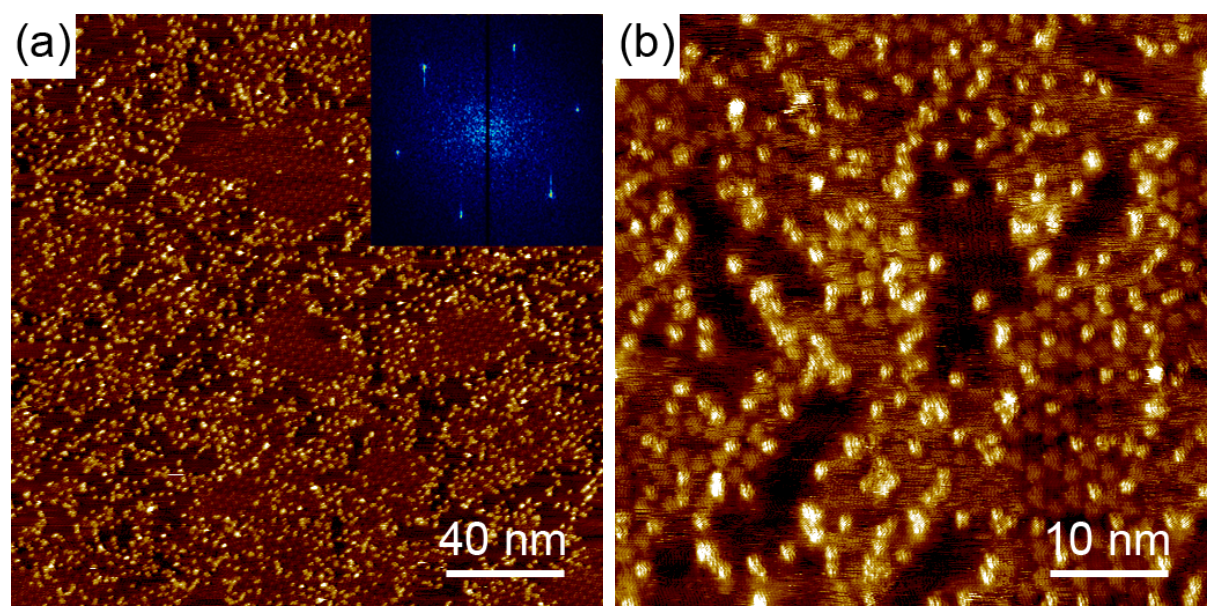

Figure S10. STM images, recorded at the 1-phenyloctane/graphite interface, of a functionalized graphite surface, after DBA-OC6 templated grafting under CA conditions. (a) Large area image ( $V_{\text {bias }}$ $=-0.60 \mathrm{~V}, I_{\text {set }}=30 \mathrm{pA}$ ). Inset: corresponding 2D-FFT image, showing six bright spots. (b) Small area image $\left(V_{\text {bias }}=-0.60 \mathrm{~V}, I_{\text {set }}=30 \mathrm{pA}\right)$. The bright dots are the grafted molecules. The faint bright spots are the DBA units of the SAMN template. 


\section{Removing Template Molecules by Washing with Hot Toluene}

Removal of the template molecules was attempted by solvent rinsing using hot chloroform $\left(20 \mathrm{~mL}, 60{ }^{\circ} \mathrm{C}\right)$. However, STM observations confirmed that not all template molecules could be removed in this way. Therefore, we used hot toluene $(20 \mathrm{~mL})$ as the rinsing solvent because of its higher boiling point. After washing twice at $100{ }^{\circ} \mathrm{C}$ for $2 \mathrm{~h}$ in toluene, the surface analysis by STM revealed that the grafted aryl units remained, while DBA molecules were removed from the surface (Figure S11a). Raman characterization of the surface affords the $I_{\mathrm{D}} / I_{\mathrm{G}}$ value of $0.049 \pm 0.003$ (Figure $\mathrm{S} 11 \mathrm{~b})$, which is slightly smaller than that before washing $\left(I_{\mathrm{D}} / I_{\mathrm{G}}=0.059 \pm 0.005\right)$.
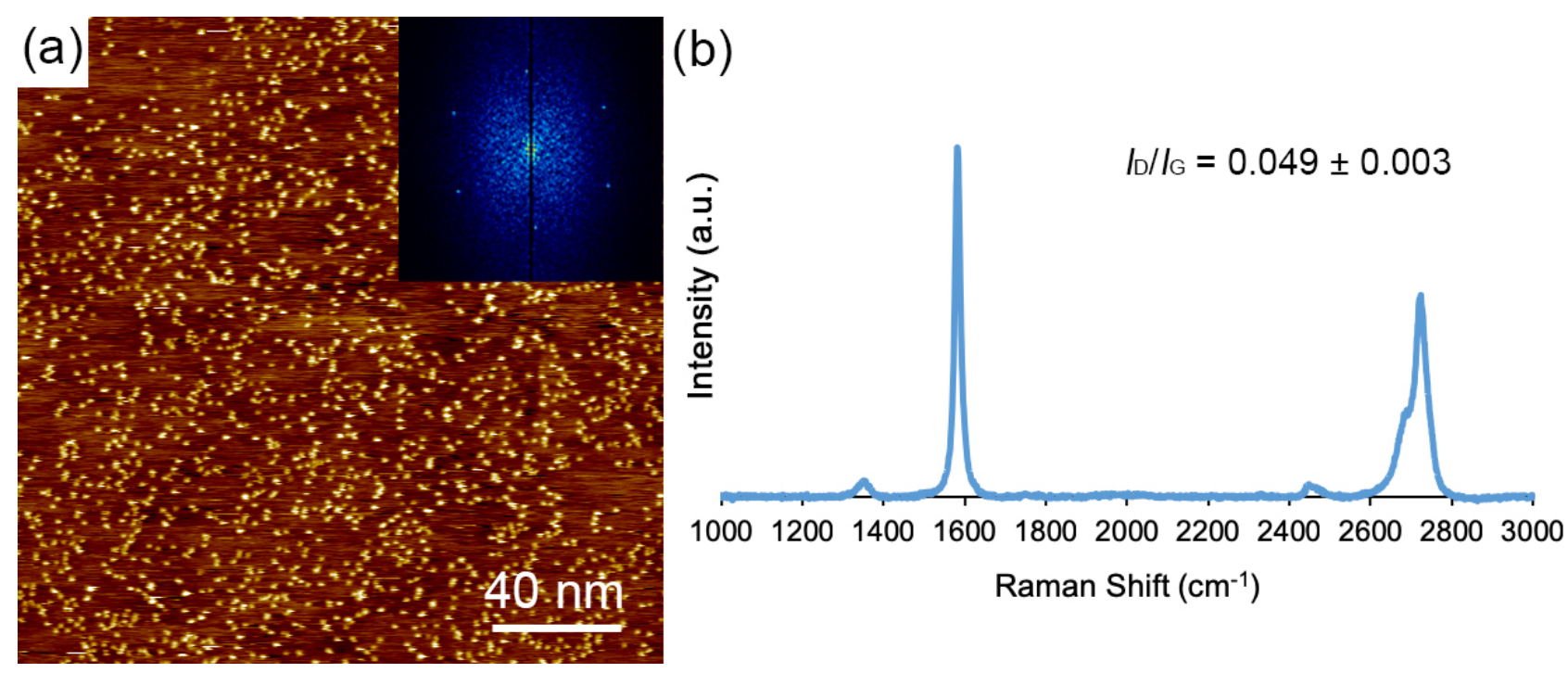

Figure S11. (a) STM image of the functionalized surface, created using a DBA-OC6 template layer, after washing with hot toluene $\left(20 \mathrm{~mL}, 100{ }^{\circ} \mathrm{C}\right)$. The STM observations were performed at the 1phenyloctane/graphite interface. The DBA-OC6 molecules are completely removed by simple solvent washing. A 2D-FFT inset shows that the hexagonal periodicity of the sample remains intact. Image parameters are $V_{\text {bias }}=-0.90 \mathrm{~V}$ and $I_{\text {set }}=50 \mathrm{pA}$. (b) Raman spectrum after washing the surface. Mean $I_{\mathrm{D}} / I_{\mathrm{G}}$ is $0.049 \pm 0.003$. 


\section{Positional Analysis on Grafted Molecular Units with Respect to Templates, DBA-OC4 and}

\section{DBA-OC6}

The location of the bright features with respect to the DBA honeycomb networks was analyzed using small area, enlarged STM images of the functionalized surfaces, where both the grafted aryl units and DBA molecules were visualized. The typical apparent height of the triangular cores of DBAs is less than $0.1 \mathrm{~nm}$, while it is over $0.2 \mathrm{~nm}$ for the grafted aryl units (Figure S12). Figures S13a and S14a are high resolution STM images of the functionalized surfaces using DBAOC4 and DBA-OC6 as the templates. In Figures S13b and S14b, white tapes of $1 \mathrm{~nm}$ width overlaid on the image connect the DBA triangular cores representing the porous networks. The DBA networks are often disturbed by the grafted species. Green dots in the Figures S13c and S14c are grafted species in DBA-OCn network pores. The distribution of the number of grafted molecules in the pores is summarized in Table 2 in the main text.
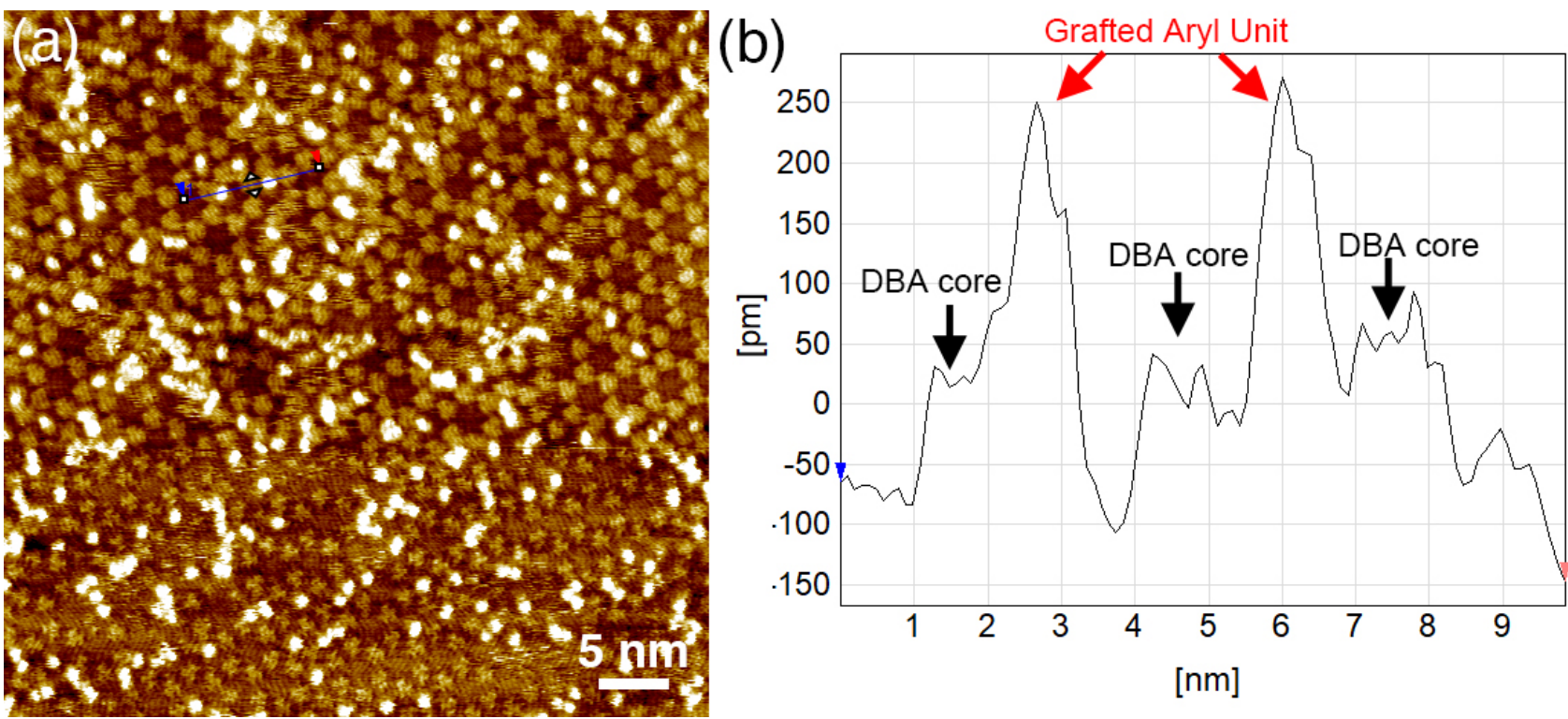

Figure S12. (a) High resolution STM image of the functionalized graphite surface after DBA-OC6 templated grafting in 1-phenyloctane $\left(V_{\text {bias }}=-0.60 \mathrm{~V}, I_{\text {set }}=30 \mathrm{pA}\right)$. (b) Apparent height profile along the blue line in (a). 

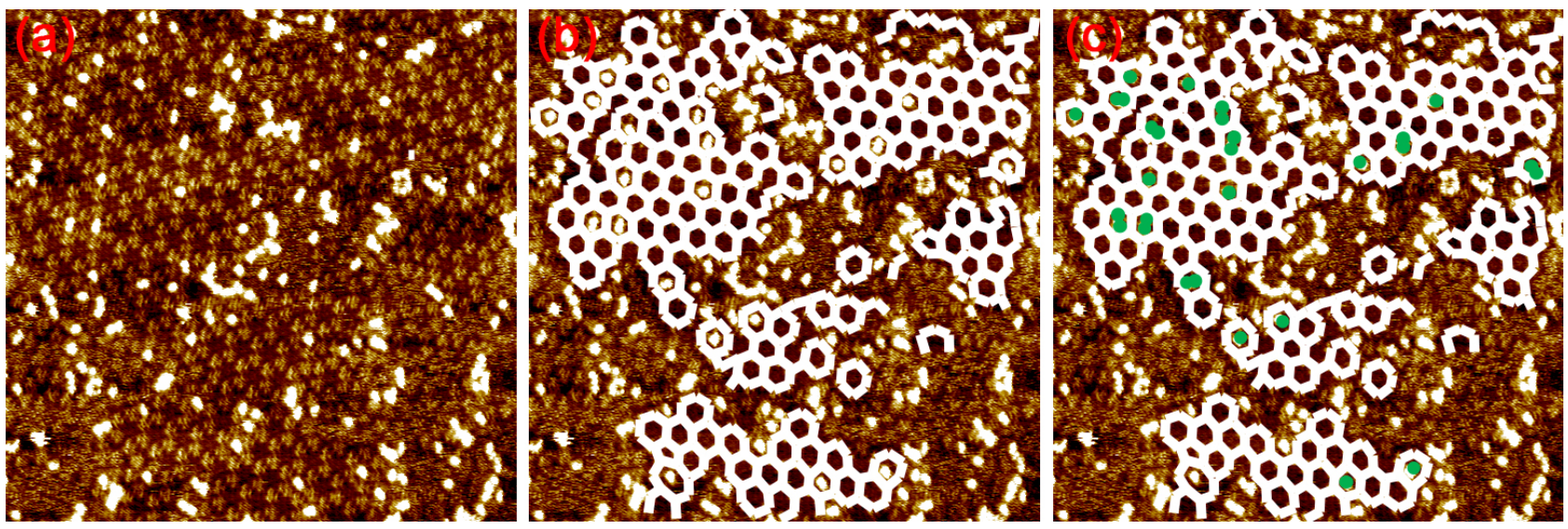

Figure S13. High resolution STM image $(50 \mathrm{~nm} \times 50 \mathrm{~nm})$ of the functionalized graphite surface using DBA-OC4 as template molecules. (a) original image, (b) image with white tapes that connect the DBA cores, and (c) image with green and yellow disks. Green disks indicate bright features within the pores. Yellow disks though not included in this image, indicate bright features that overlaps with white tapes.
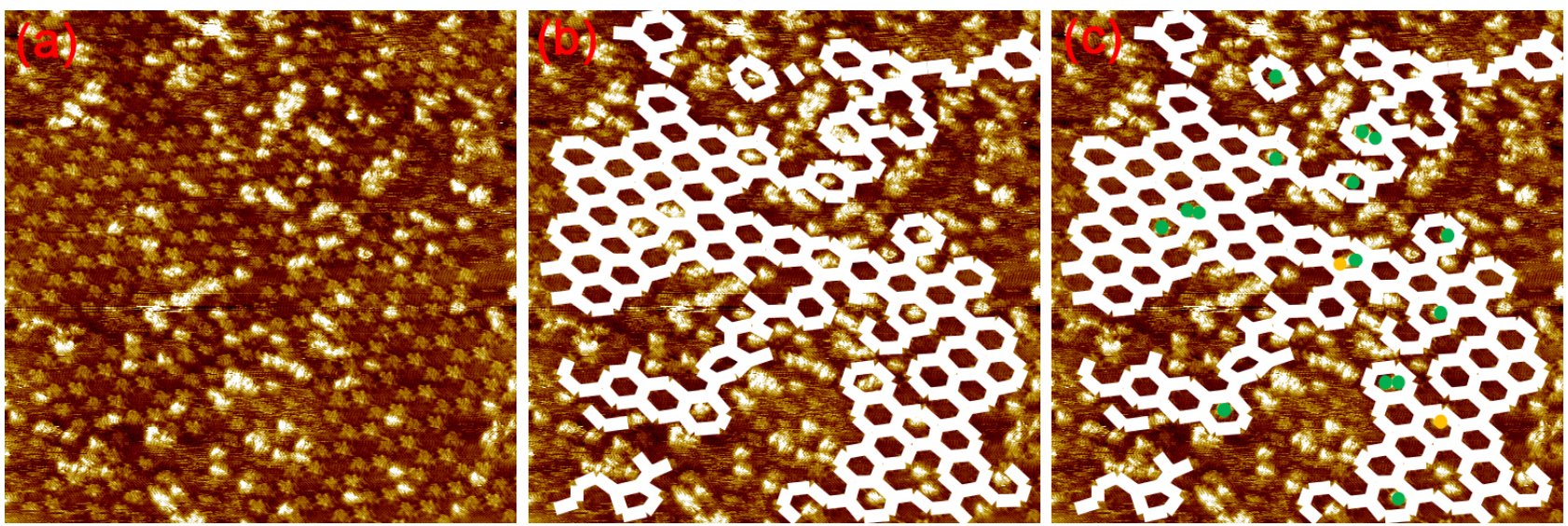

Figure S14. High resolution STM image $(40 \mathrm{~nm} \times 40 \mathrm{~nm})$ of the functionalized graphite surface using DBA-OC6 as template molecules. (a) original image, (b) image with white tapes that connect the DBA cores, and (c) image with green and yellow disks. Green disks indicate bright features within the pores. Yellow disks indicate bright features that overlap with white tapes. 


\section{Analysis on Global Correspondence}

For each template molecule, five large area STM images of the functionalized surfaces (200 $\mathrm{nm} \times 200 \mathrm{~nm}, 512$ pixels $\times 512$ pixels) were used for the following analysis (Figure S15a). For the calibration of the image size, a two-dimensional Fast Fourier Transform (2D-FFT) was applied using an extended Fourier analysis module of SPIP ${ }^{\mathrm{TM}}$ software. The lateral dimensions of the original STM image were calibrated using observed hexagonal periodicities in the 2D-FFT image to fit ideal hexagonal periodicities (i.e., the unit cells of the template DBA-OCn networks) to reduce the thermal drift effects. The functionalized surface without the template network was used as the reference sample, and in this case the lateral calibration was not applied. The $\mathrm{x}, \mathrm{y}$-coordinates of the centers of each bright feature (grafted molecular unit) in these calibrated or not calibrated STM images were determined using Particle \& Pore Analysis module of SPIP ${ }^{\mathrm{TM}}$ software (Figure S15b), in which the origin of the coordinate is an image center. To uniquely consider the grafted species, an apparent height threshold for the detection was set to $0.15 \mathrm{~nm}$. This value was determined by the apparent height analysis of a high resolution image (see Figure S12). This analysis led to the experimentally derived coordinates.

In addition, two other sets of coordinates were generated through in-house programs written in Python (version 3.6). In the perfect reference hexagonal network, the coordinates match those defined by the unit cell parameters of the DBA-OCn templates considered (Figure S15c). The random reference matches the number (surface density) of experimentally observed grafted molecules, though randomly positioned, which was generated through Mote Carlo method.

A protocol was developed to determine "hits", where a "hit" is defined as a match between the $\mathrm{x}, \mathrm{y}$-coordinates of a grafted molecule, whose coordinates are experimentally derived (i.e., experimentally derived coordinates) or generated in other ways (i.e., random reference, Figure S15d), and those of the perfect reference hexagonal network. Such perfect reference is divided into four square segments $(100 \mathrm{~nm} \times 100 \mathrm{~nm})$. Each segment is then rotated and moved laterally to maximize the number of matches within a given tolerance $(0.22,0.30,0.37,0.45,0.55,0.655,0.70,0.80,0.90$, and $1.00 \mathrm{~nm}$, Figures S16). We set the minimum tolerance of $0.22 \mathrm{~nm}$ slightly larger than the half of a pixel size $(0.20 \mathrm{~nm}$ for the image of $200 \mathrm{~nm} \times 200 \mathrm{~nm}$ and 512 pixels $\times 512$ pixels size $)$.

We have defined the following parameters to evaluate the quality of the grafting:
E: number of hits for experimentally derived coordinates
$\mathrm{R}$ : number of hits for random reference 
We have then defined the following ratio to evaluate the quality of the grafting:

E/R: In absence of a templating effect, this ratio will approach 1. The stronger the templating effect, the larger this ratio.

In this approach, the positive impact of the DBA-OCn templates in guiding the grafting is clearly visible (Table S2, Figure S17). The parameter (E/R) indicates that the grafting process is to a significant extent "non-random", even for the smallest tolerances considered. 

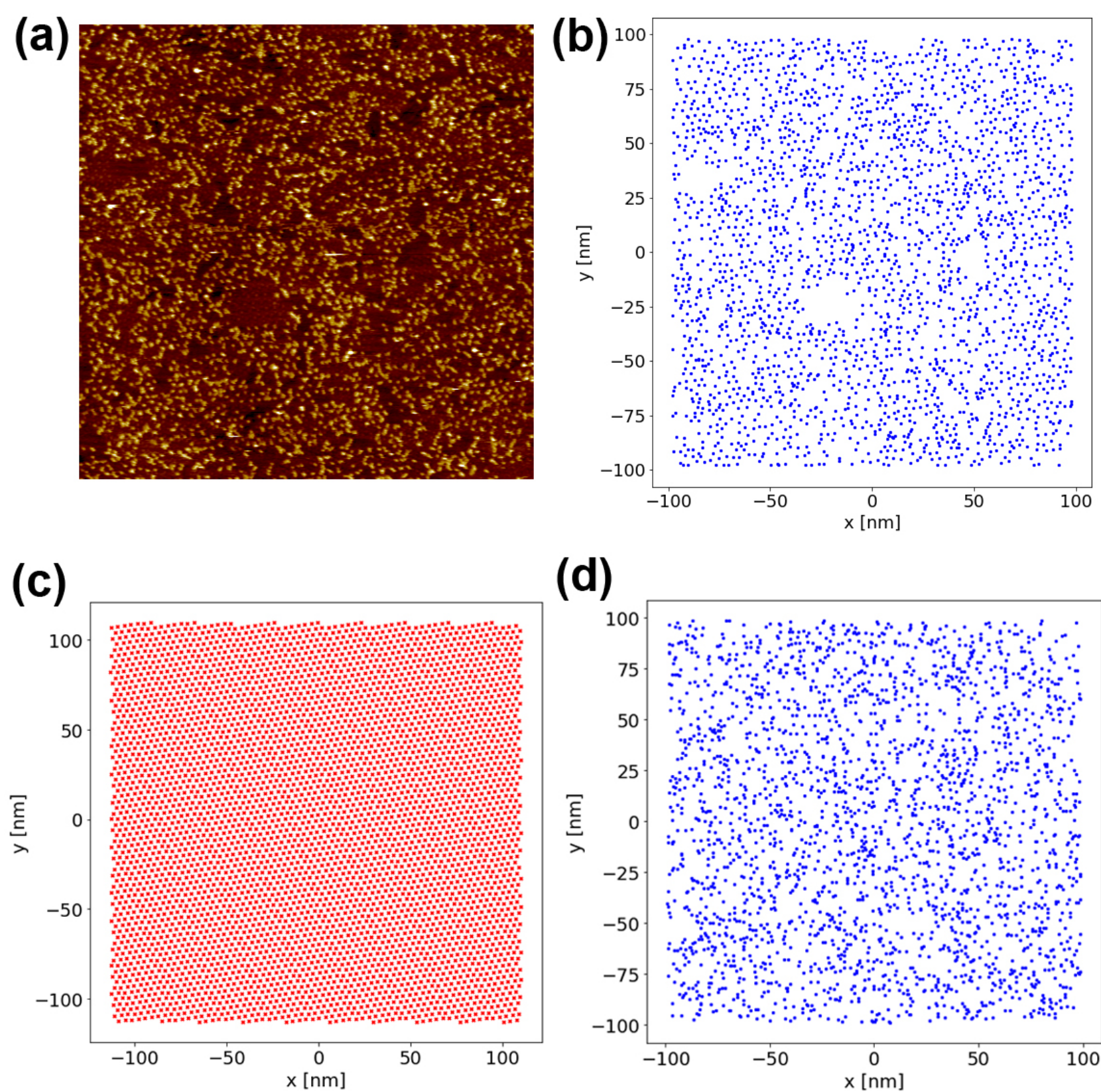

(d)

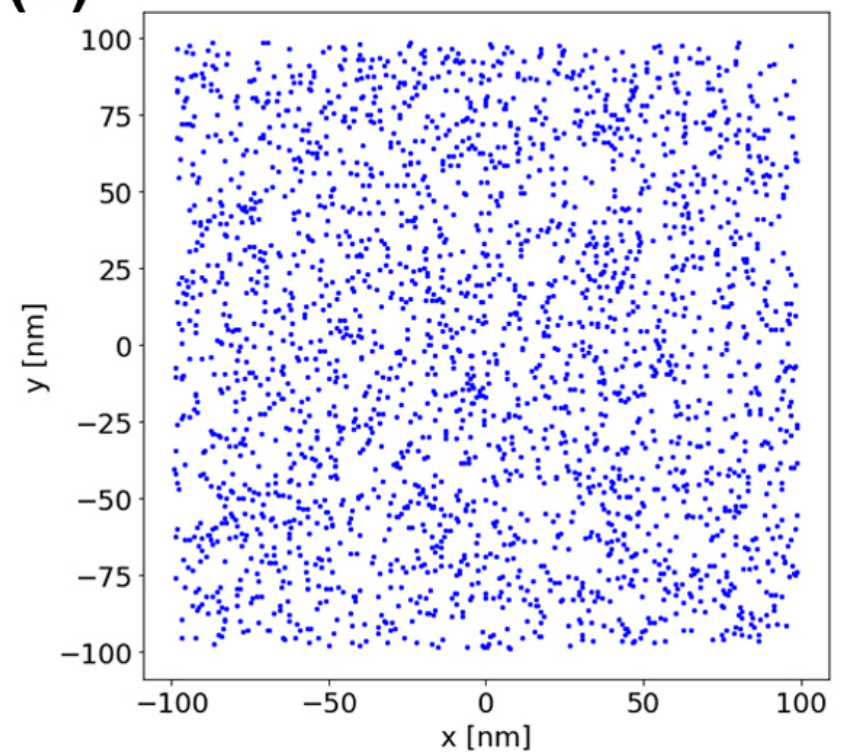

Figure S15. (a) Typical calibrated STM image of the functionalized surface using the DBA-OC8 molecular template $(196 \mathrm{~nm} \times 196 \mathrm{~nm}$ and 472 pixels $\times 472$ pixels $)$. (b) $\mathrm{x}, \mathrm{y}$-Coordinates of the bright features (grafted molecular species), giving the experimentally derived coordinates. (c) The perfect reference lattice. (d) A random reference lattice with the same particle density as in image (a). 

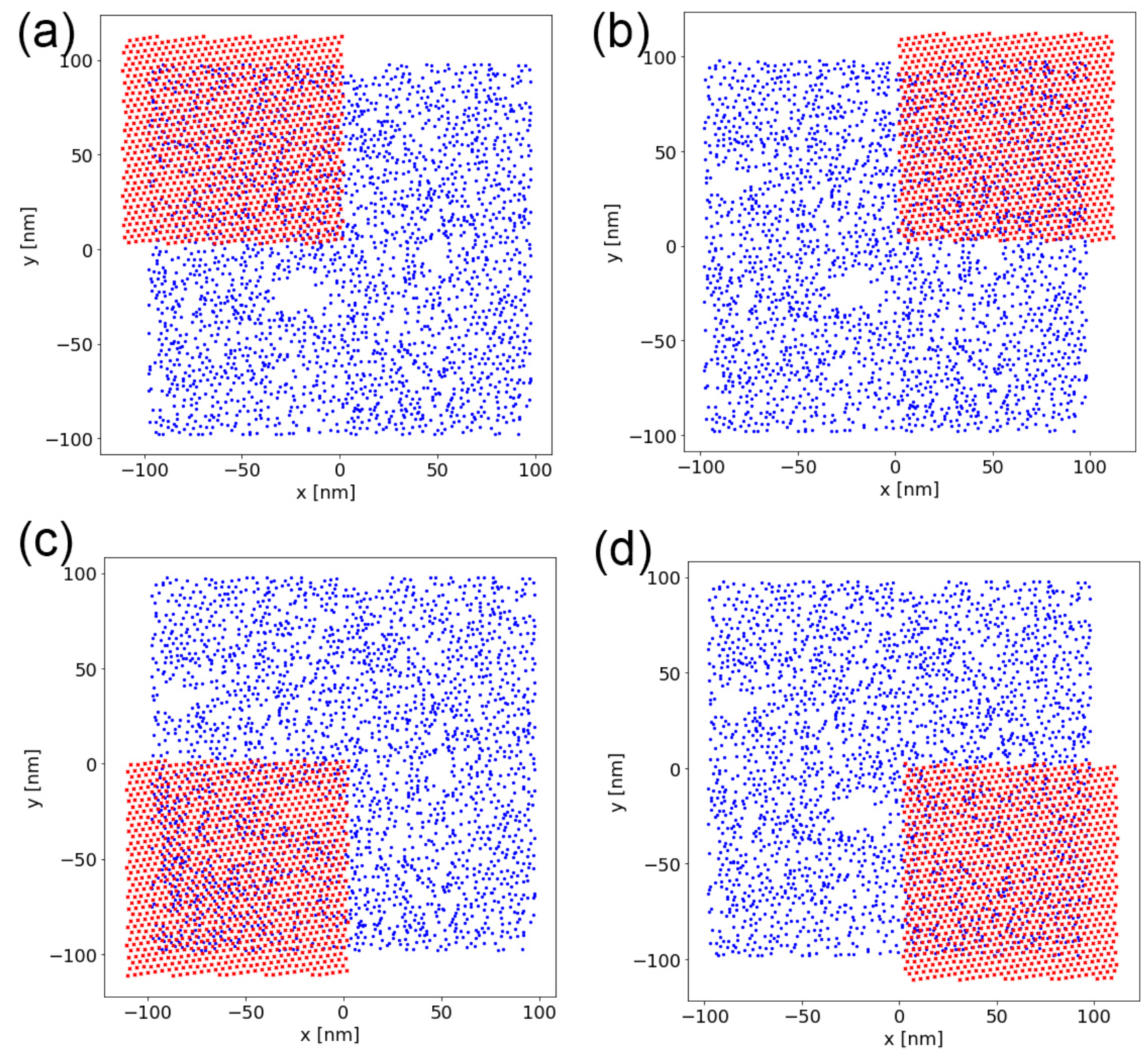

Figure S16. Approach for finding the maximum number of hits between the experimentally derived coordinate and perfect reference lattices $(\mathrm{a}-\mathrm{d})$. Blue particles are the experimentally derived coordinates (as in Figure S15b). Red particles are those of the perfect reference lattice, grouped into four segments. 


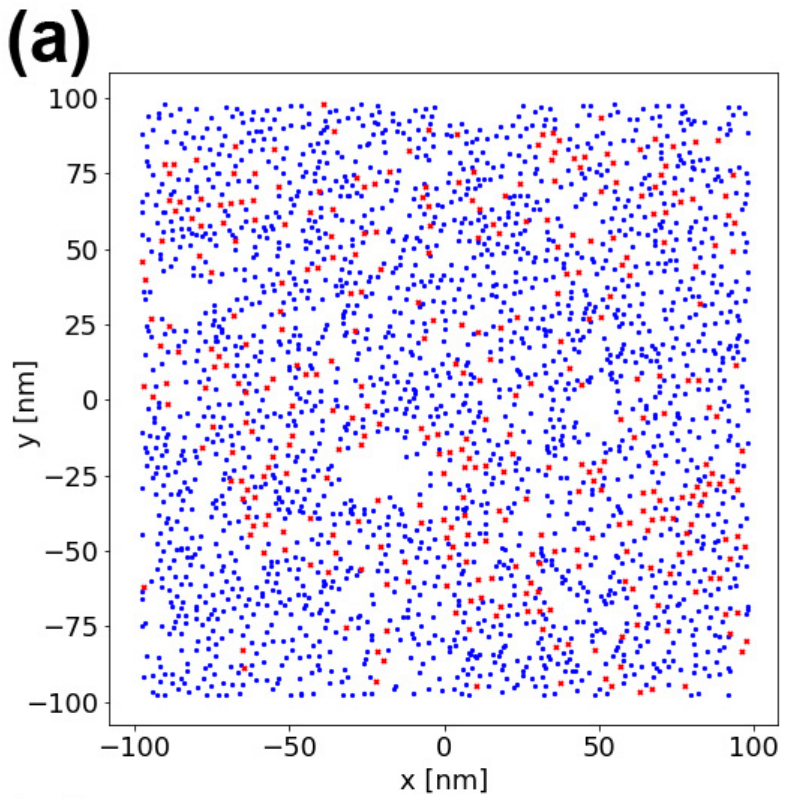

(c)

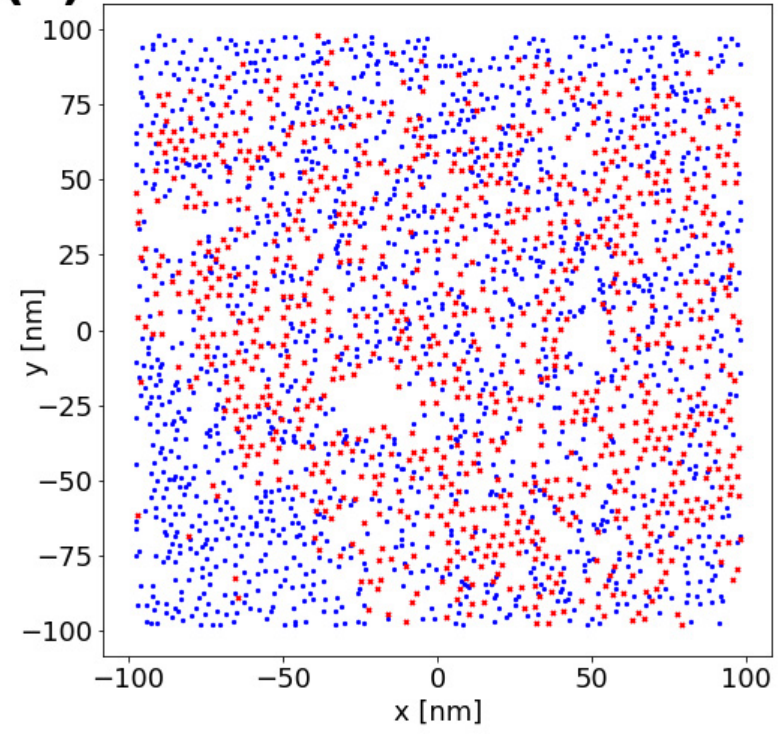

(b)

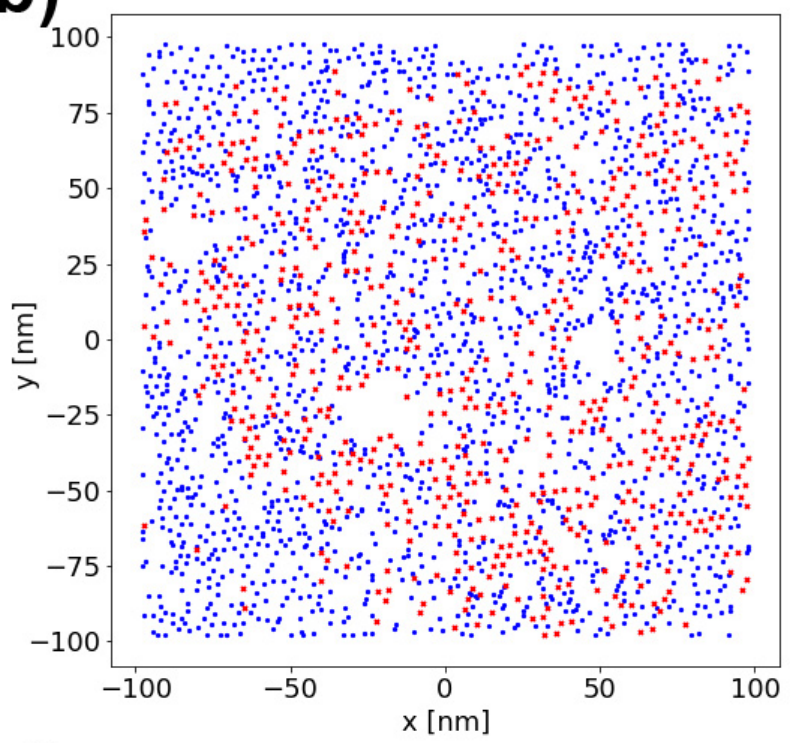

(d)

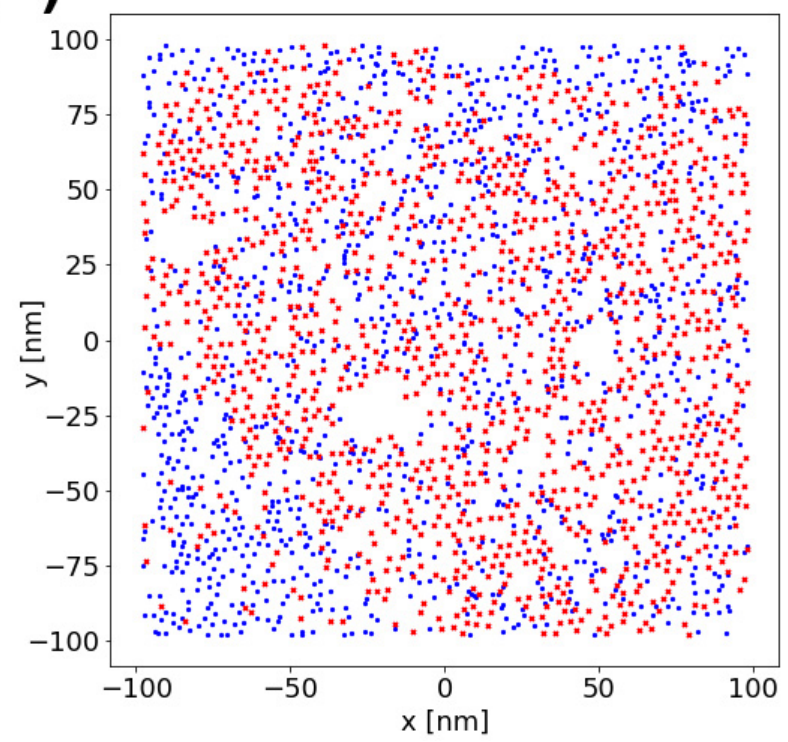

Figure S17. Number of "hits" (red) for various tolerances, $0.37 \mathrm{~nm}$ for (a), $0.55 \mathrm{~nm}$ for (b), $0.70 \mathrm{~nm}$ for (c), and $0.90 \mathrm{~nm}$ for (d). Blue particles are the experimentally derived coordinates (as in Figure $\mathrm{S} 15 b)$. 
(a)

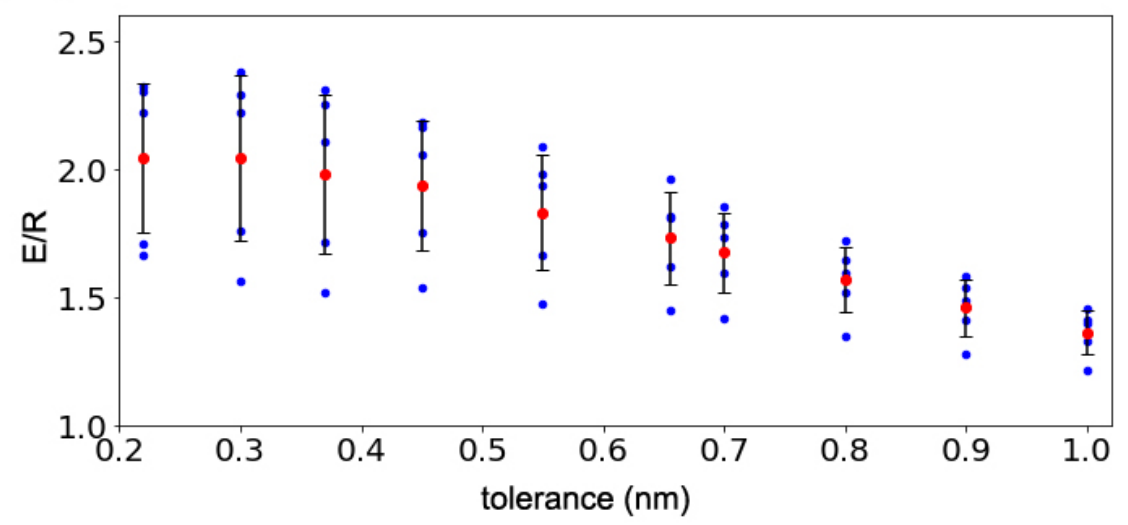

(b)

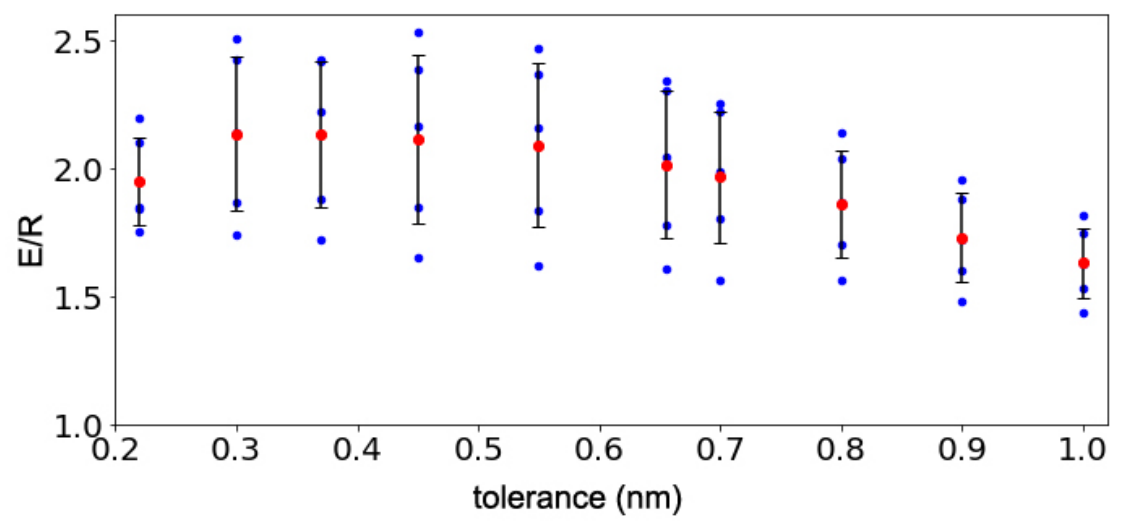

(c)

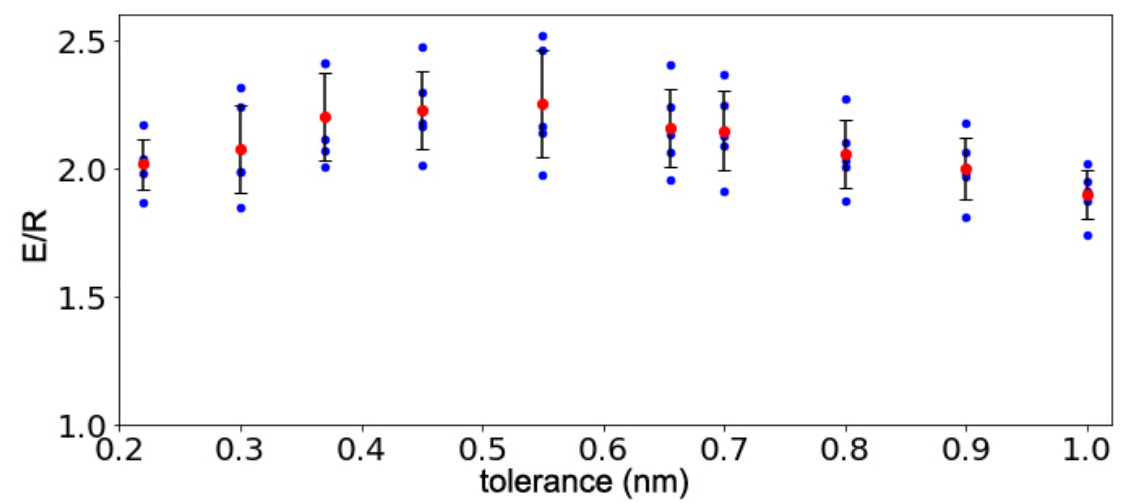

Figure S18. Ratio of the number of hits for the experimentally derived coordinates to the random reference (E/R) for various set tolerances for the DBA-OC4 template (a), for the DBA-OC6 template (b), and for the DBA-OC8 template (c). Blue dots are the values for individual images and red dots are the average for a given tolerance $(\mathrm{nm})$. Error bars are standard deviations. 
Table S2. E/R for a Given Range of Accepted Tolerance

\begin{tabular}{|c|c|c|c|c|c|c|c|c|c|c|}
\hline \multirow{2}{*}{$\begin{array}{l}\text { template } \\
\text { molecule }\end{array}$} & \multicolumn{10}{|c|}{ accepted tolerance $(\mathrm{nm})$} \\
\hline & 0.22 & 0.30 & 0.37 & 0.45 & 0.55 & 0.655 & 0.70 & 0.80 & 0.90 & 1.00 \\
\hline \multirow{3}{*}{ DBA-OC4 } & 2.05 & 2.04 & 1.98 & 1.94 & 1.83 & 1.73 & 1.68 & 1.57 & 1.46 & 1.37 \\
\hline & \pm & \pm & \pm & \pm & \pm & \pm & \pm & \pm & \pm & \pm \\
\hline & 0.33 & 0.36 & 0.35 & 0.28 & 0.25 & 0.20 & 0.17 & 0.14 & 0.12 & 0.09 \\
\hline \multirow{3}{*}{ DBA-OC6 } & 1.95 & 2.14 & 2.13 & 2.12 & 2.09 & 2.02 & 1.97 & 1.86 & 1.73 & 1.63 \\
\hline & \pm & \pm & \pm & \pm & \pm & \pm & \pm & \pm & \pm & \pm \\
\hline & 0.19 & 0.33 & 0.32 & 0.37 & 0.36 & 0.32 & 0.29 & 0.23 & 0.19 & 0.15 \\
\hline \multirow{3}{*}{ DBA-OC8 } & 2.02 & 2.08 & 2.20 & 2.23 & 2.25 & 2.16 & 2.15 & 2.06 & 2.00 & 1.90 \\
\hline & \pm & \pm & \pm & \pm & \pm & \pm & \pm & \pm & \pm & \pm \\
\hline & 0.11 & 0.19 & 0.19 & 0.17 & 0.23 & 0.17 & 0.17 & 0.15 & 0.13 & 0.10 \\
\hline \multirow{2}{*}{$\begin{array}{l}\text { without } \\
\text { template }^{a}\end{array}$} & 0.99 & 0.98 & 1.02 & 1.03 & 1.04 & 1.00 & 1.00 & 1.00 & 1.00 & 0.99 \\
\hline & $\begin{array}{c} \pm \\
0.08\end{array}$ & $\begin{array}{c} \pm \\
0.09 \\
\end{array}$ & $\begin{array}{c} \pm \\
0.07 \\
\end{array}$ & $\begin{array}{c} \pm \\
0.07 \\
\end{array}$ & $\begin{array}{c} \pm \\
0.07\end{array}$ & $\begin{array}{c} \pm \\
0.05 \\
\end{array}$ & $\begin{array}{c} \pm \\
0.06 \\
\end{array}$ & $\begin{array}{c} \pm \\
0.05\end{array}$ & $\begin{array}{c} \pm \\
0.05\end{array}$ & $\begin{array}{c} \pm \\
0.05\end{array}$ \\
\hline
\end{tabular}

${ }^{a}$ The periodicity of the perfect reference hexagonal network used for this analysis is the unit cell parameters of the DBA-OC4 template. 


\section{2D FFT Analysis of STM Image of Monolayer Formed by DBA-OC6}
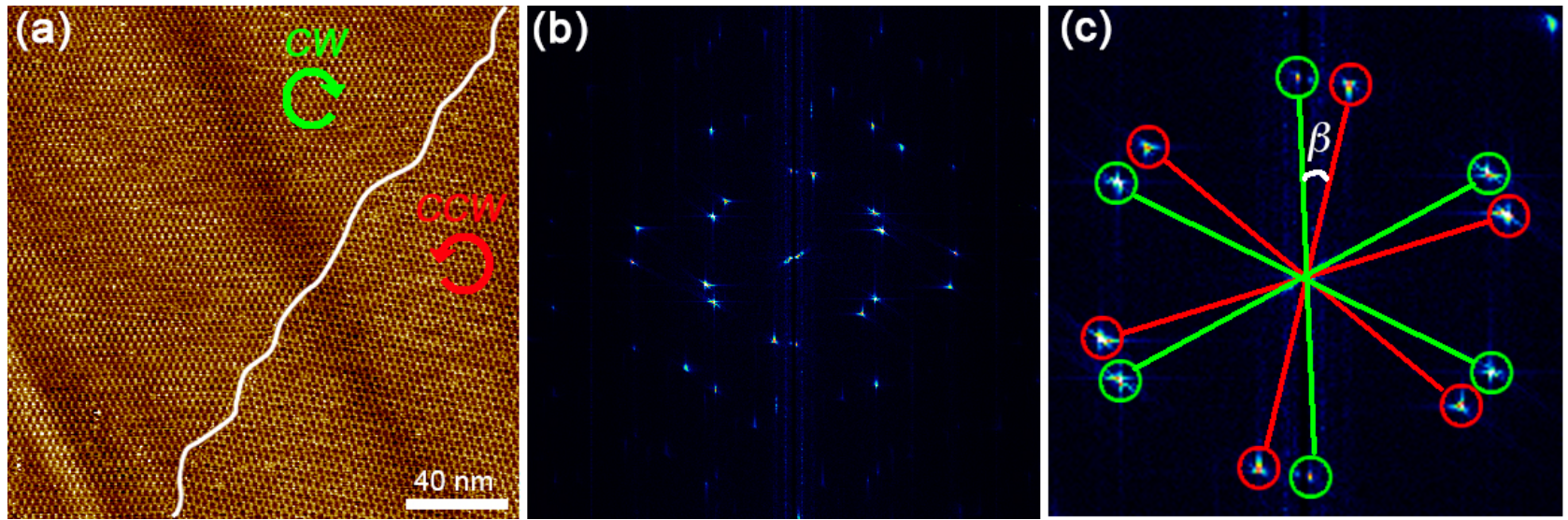

Figure S19. (a) Large area STM image of a monolayer formed by DBA-OC6 at the 1phenyloctane/graphite interface $\left(V_{\text {bias }}=-0.60 \mathrm{~V}, I_{\text {set }}=30 \mathrm{pA}\right)$. White line in (a) is a boundary of $C W$ and $C C W$ honeycomb structures. (b, c) 2D-FFT images of image (a). Two sets of six bright spots confirm two different orientations of the hexagonal alignments. These are distinguished in zoomed image (c) by green and red circles, each derived from $C W$ and $C C W$ domains. The mean angle $(\beta)$ between the green and red lines connecting the spots and the center of the image is $13 \pm 1^{\circ}$. 


\section{Porous Self-Assembled Monolayers Formed by cDBA-OC6(S)-OC6}

Self-assembled molecular network formation by cDBA-OC6 $(S)-0 C 6$ at the liquid/graphite interface was investigated in two solvents, $\mathrm{PO}$ and 1,2,4-trichlorobenzene (TCB). Both $C W$ and $C C W$ honeycomb structures co-exist in PO independent of solute concentration and annealing treatments. In contrast, in the case of TCB $\left(2.0 \times 10^{-5} \mathrm{M}\right)$, this DBA exclusively forms a homochiral $C C W$ honeycomb structure upon annealing at $80^{\circ} \mathrm{C}$ for $5 \mathrm{~h}$ in a sealed oven. All STM images were recorded at the $\mathrm{TCB} / \mathrm{graphite}$ interface at room temperature.

Figure S20 displays an STM image of SAMN formed by cDBA-OC6(S)-OC6 at the TCB/graphite interface. The domain size of the $C C W$ honeycomb structure of cDBA-OC6(S)-OC6 is typically over $200 \mathrm{~nm} \times 200 \mathrm{~nm}$. In the $C C W$ honeycomb structure, the three chiral chains of cDBA-OC6(S)-OC6 are located at the rims of the hexagonal pore because of steric constraints. Unit cell parameters are $\mathrm{a}=\mathrm{b}=3.2 \pm 0.1 \mathrm{~nm}$ and $\gamma=60 \pm 1^{\circ}$, which are identical to those of DBA-OC6. Mean angle $\alpha$ between the unit cell vector and one of the normals to the main axes of graphite is -6.7 $\pm 0.8^{\circ}$.

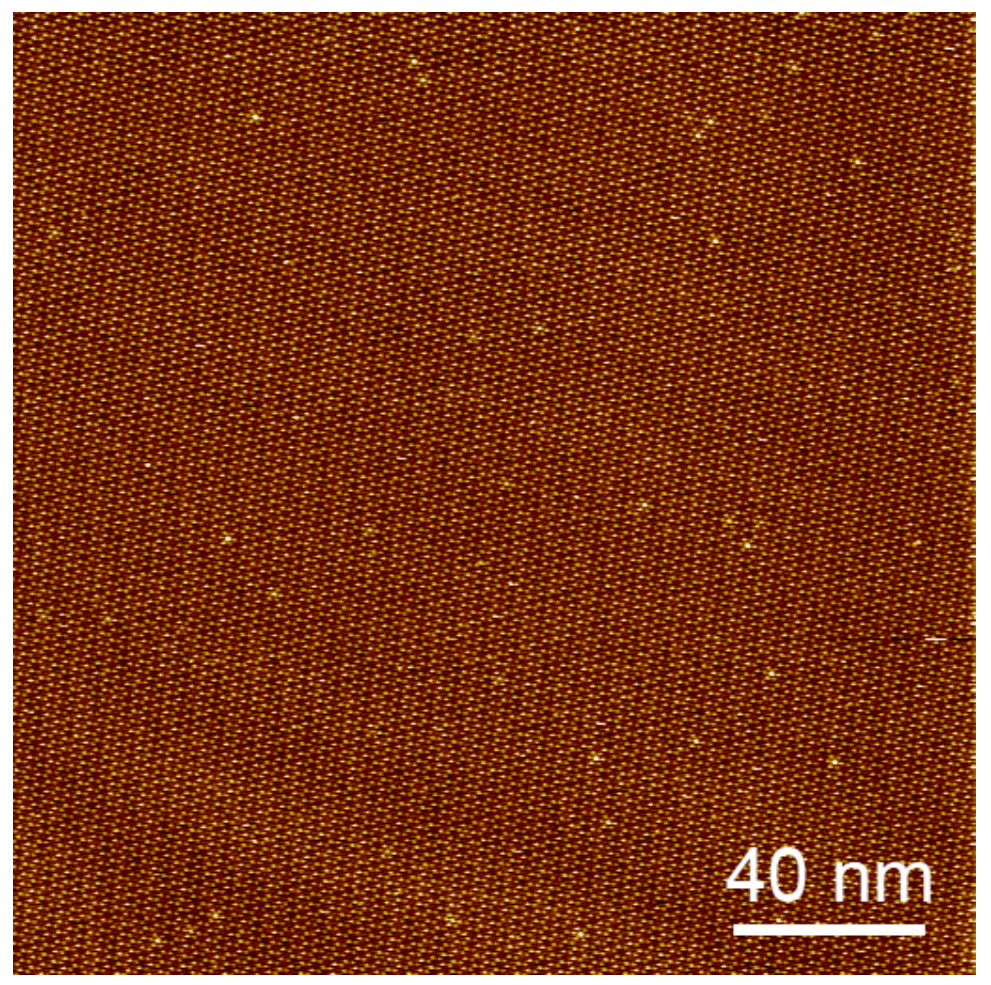

Figure S20. Large area STM image of SAMN formed by cDBA-OC6(S)-OC6 at the TCB/graphite interface $\left(V_{\text {bias }}=-0.72 \mathrm{~V}, I_{\text {set }}=80 \mathrm{pA}\right)$. An extended domain covers the whole image. 


\section{Templated Grafting at Double Layer Conditions Using TCB}

Chemical functionalization of the graphite surface through EC reduction of TMeOD was conducted in the aqueous solution/TCB double layer conditions without a templating mask. EC reduction was carried out in cyclic voltammogram $(\mathrm{CV})$ mode (a single cycle from +0.20 to $-0.25 \mathrm{~V}$ vs. $\mathrm{Ag} / \mathrm{AgCl}, 0.1 \mathrm{~V} / \mathrm{s}$ ). A large irreversible reduction wave appeared at $-0.17 \mathrm{~V}$ (Figure S21a). After the EC functionalization, the graphite surface was subjected to spectroscopic characterization using Raman spectroscopy with excitation laser wavelength of $532 \mathrm{~nm}$ (Figure S21b). The appearance of the graphite defect band (D-peak) at $1350 \mathrm{~cm}^{-1}$ confirms surface covalent bond formation. The $I_{\mathrm{D}} / I_{\mathrm{G}}$ value of this sample is $0.042 \pm 0.001$. Local structural analysis of the functionalized graphite surface by means of STM at the TCB/graphite interface revealed that there are numerous bright features that are assigned to individual trimethoxyphenyl molecular units (Figure S21c). A two-dimensional Fast Fourier Transform (2D-FFT) image (Figure S21c: inset) only shows a large dim bright round feature, confirming positionally non-controlled grafting.
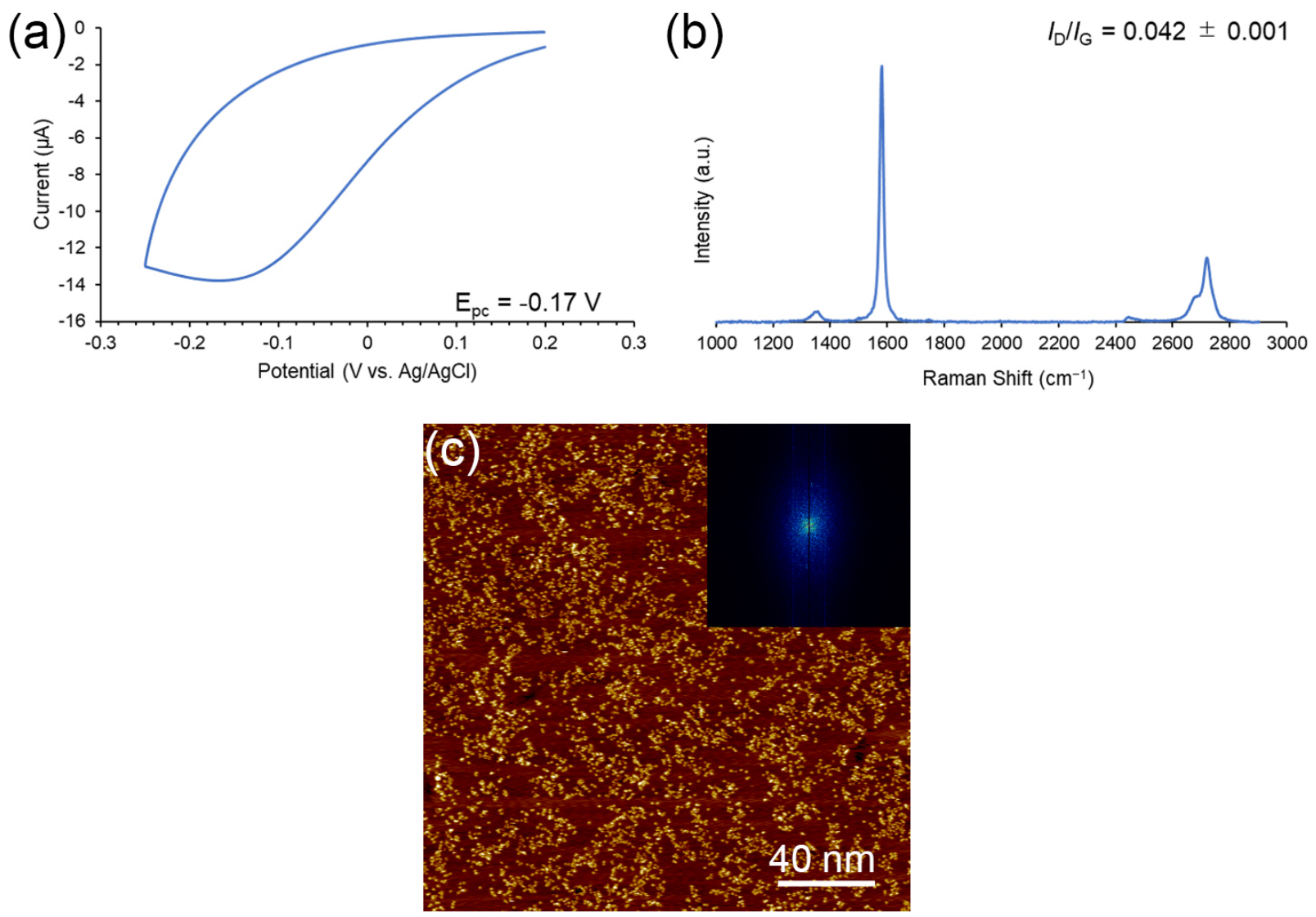

Figure S21. (a) Cyclic voltammogram during EC grafting of graphite using TMeOD under solution double layer conditions (a single cycle from +0.20 to $-0.25 \mathrm{~V}$, vs. $\mathrm{Ag} / \mathrm{AgCl}, 0.1 \mathrm{~V} / \mathrm{sec}$ ). TCB was used as the organic solvent layer. (b) Raman spectrum after drying the surface. Mean $I_{\mathrm{D}} / I_{\mathrm{G}}$ is $0.042 \pm$ 0.001. (c) STM image of the functionalized graphite surface recorded at the TCB/graphite interface $\left(V_{\text {bias }}=-0.60 \mathrm{~V}, I_{\text {set }}=50 \mathrm{pA}\right)$. The inset is the corresponding 2D-FFT image, showing no periodicity of the bright features. 
Nanopatterned covalent grafting was attempted under phase separated solution double layer conditions using a solution of cDBA-OC6(S)-OC6 in TCB $(40 \mu \mathrm{L})$ as an interfacial solvent layer. In $\mathrm{CV}$, a large irreversible wave at $-0.17 \mathrm{~V}$ was recorded (Figure S22a). The reduction peak potential is comparable to that without the template molecules. Raman spectroscopic characterization confirms the appearance of the D-peak at $1350 \mathrm{~cm}^{-1}$ and $I_{\mathrm{D}} / I_{\mathrm{G}}$ value is $0.039 \pm 0.003$, indicating covalent bond formation (Figure S22b). STM observations of the functionalized graphite in TCB revealed that individual trimethoxyphenyl units arranged in a hexagonal manner (Figure S22c). This is confirmed by a 2D-FFT of the STM image which shows the hexagonal periodicity with a mean periodicity of $2.6 \pm 0.1 \mathrm{~nm}$ (Figure S22c: inset). This periodicity agrees with the pore-to-pore distance of cDBAOC6(S)-OC6 molecular network $(2.8 \pm 0.1 \mathrm{~nm})$. Sometimes, both the covalently attached trimethoxyphenyl units and adsorbed DBA molecules could be visualized at the same time (Figure S22d).
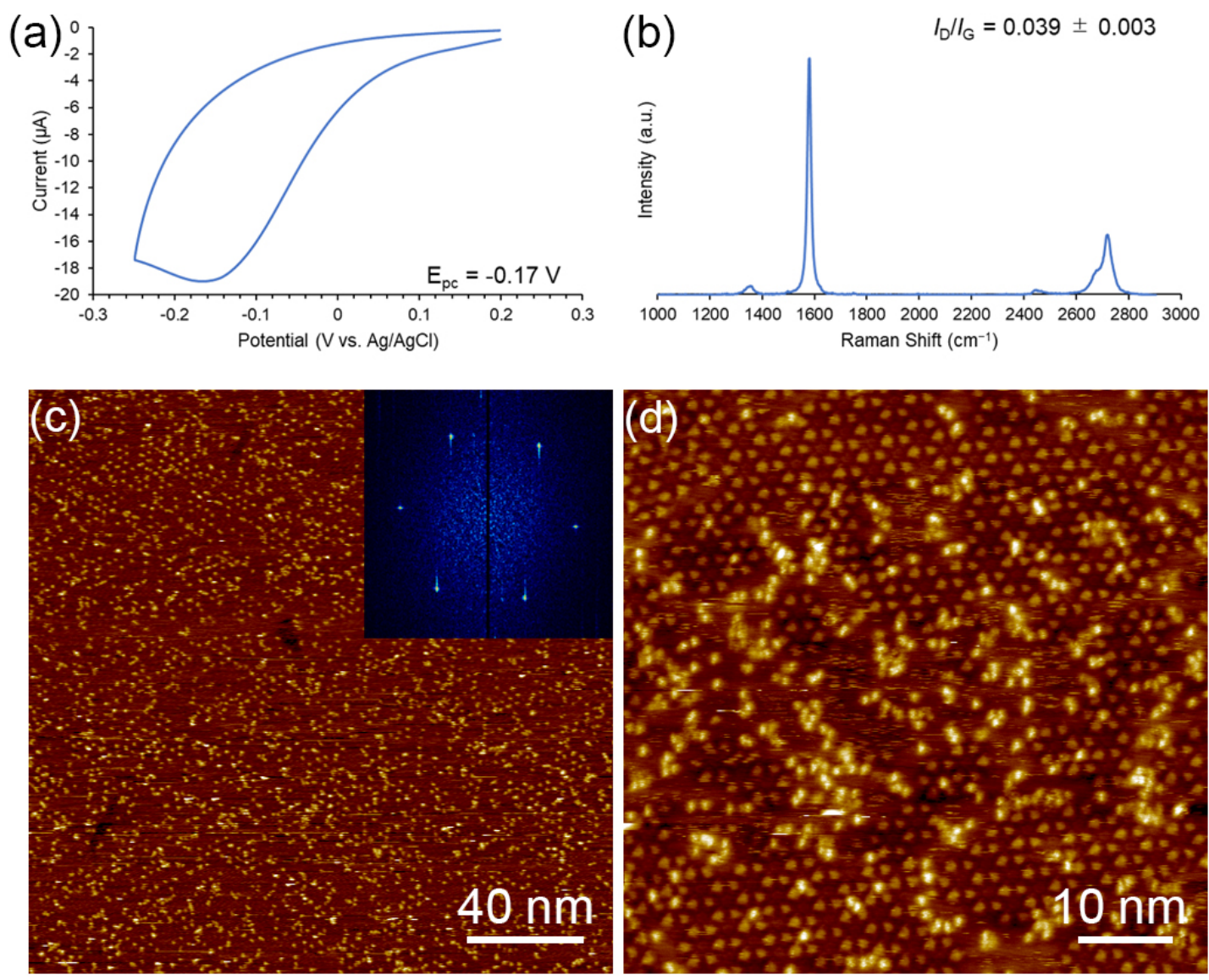

Figure S22. (a) Cyclic voltammogram during EC grafting of graphite using TMeOD in the presence of a solution of cDBA-OC6(S)-OC6 in TCB as an interfacial layer (a single cycle from +0.20 to $0.25 \mathrm{~V}$, vs. $\mathrm{Ag} / \mathrm{AgCl}, 0.1 \mathrm{~V} / \mathrm{sec}$ ). (b) Raman spectrum after drying the surface. Mean $I_{\mathrm{D}} / I_{\mathrm{G}}$ is $0.039 \pm$ 0.003. (c, d) STM images of the functionalized graphite surface after CDBA-OC6(S)-OC6 templated grafting in TCB. (c) Large area image $\left(V_{\text {bias }}=-0.60 \mathrm{~V}, I_{\text {set }}=30 \mathrm{pA}\right)$. The inset corresponds to the 2D-FFT image. Six bright spots in the 2D-FFT image confirm the hexagonal periodicity. (d) Small area image $\left(V_{\text {bias }}=-0.60 \mathrm{~V}, I_{\text {set }}=100 \mathrm{pA}\right)$. 


\section{Chirality Analysis}

Handedness (orientation) of the hexagonal arrangements of the grafted aryl groups with respect to the graphite lattice was analyzed by the angle $\delta . \delta$ is the angle between symmetry lines of the hexagonally functionalized surface (these symmetry lines are the bisectors of the angles formed by the center of the 2D-FFT image and adjacent high-intensity points (symmetry lines in turquoise, axes $A$, Figure $\mathrm{S} 23 \mathrm{~b}$ )), and reference axes (the in-plane directions normal to the main symmetry axes of graphite) of the graphite substrate underneath (black lines in Figure S23e). If the grafting preferentially occurs at the center of the pores of the DBA honeycomb structures, the periodicity and orientation of the template should be transferred to the position of the grafted aryl groups. In such case, the angle $\delta$ values should match those of the angle $\alpha$ (characteristic of the SAMN template). The angle $\delta$ is experimentally determined according to the following procedure:

(1) Large area STM images $(200 \mathrm{~nm} \times 200 \mathrm{~nm})$ of the hexagonally functionalized surface are recorded (Figure S23a).

(2) Lateral drift effects in the large area STM images are corrected for by a calibration protocol based on the unit cell parameters of DBA-OC6 or CDBA-OC6(S)-OC6 (Figure S23b). Here we assume that the template periodicity is the same as the one adopted by the grafted aryl groups.

(3) The axes $A$ (turquoise lines, bisecting the angles formed by connecting the center and adjacent high-intensity points of the 2D-FFT image) are determined from the 2D-FFT images of the hexagonally functionalized surfaces (the inset of Figure S23b).

(4) Small area STM images of the underlying graphite surface are recorded at the center of the large area STM images by changing image size and tunneling parameters. The orientation of the normals to the main graphite symmetry axes are determined from this small area STM image (Figure S23c). The imaging of the graphite surface is performed at low bias voltages (about 10 $\mathrm{mV}$ ), thereby removing grafted aryl groups and revealing the basal plane of pristine graphite (Figure S23d). ${ }^{5,6,7}$ Note that the thermal drift effect in the scanning directions associated with changing the image size is typically within $1^{\circ}$.

(5) The axes $A$ are overlaid on the selected symmetry directions of the graphite lattice (Figure S23e), defining the angle $\delta$.

From the analysis of 32 STM images of covalently functionalized graphite using the DBAOC6 template, the values for the angle $\delta$ can be grouped in two, with mean values of $+6.5 \pm 0.5^{\circ}$ and $-6.6 \pm 0.4^{\circ}$. These are consistent with the angle $\alpha$ of DBA-OC6 $\left( \pm 6.3 \pm 0.7^{\circ}\right)$. Furthermore, the appearance frequency of positive and negative $\delta$ values is roughly the same $(41 \%$ and $50 \%$, 
respectively). The remaining 9\% includes STM images with both positive and negative $\delta$ values (Figure S24), indicating the presence of mirror-image hexagonal orientations.

In case of cDBA-OC6(S)-OC6 templated grafting, based on 24 STM images, only negative angle $\delta$ values are found (Figure S25). The mean $\delta$ value is $-6.8 \pm 0.4^{\circ}$. This value agrees with the angle $\alpha$ of the CCW honeycomb structure of the cDBA-OC6 $(S)$-OC6 template layer $\left(-6.7 \pm 0.8^{\circ}\right)$. This analysis supports the hypothesis that the chirality of the honeycomb structure of the DBA SAMN is transferred to the handedness of the orientation of the pattern formed by the grafted species with respect to the graphite lattice symmetry axes.
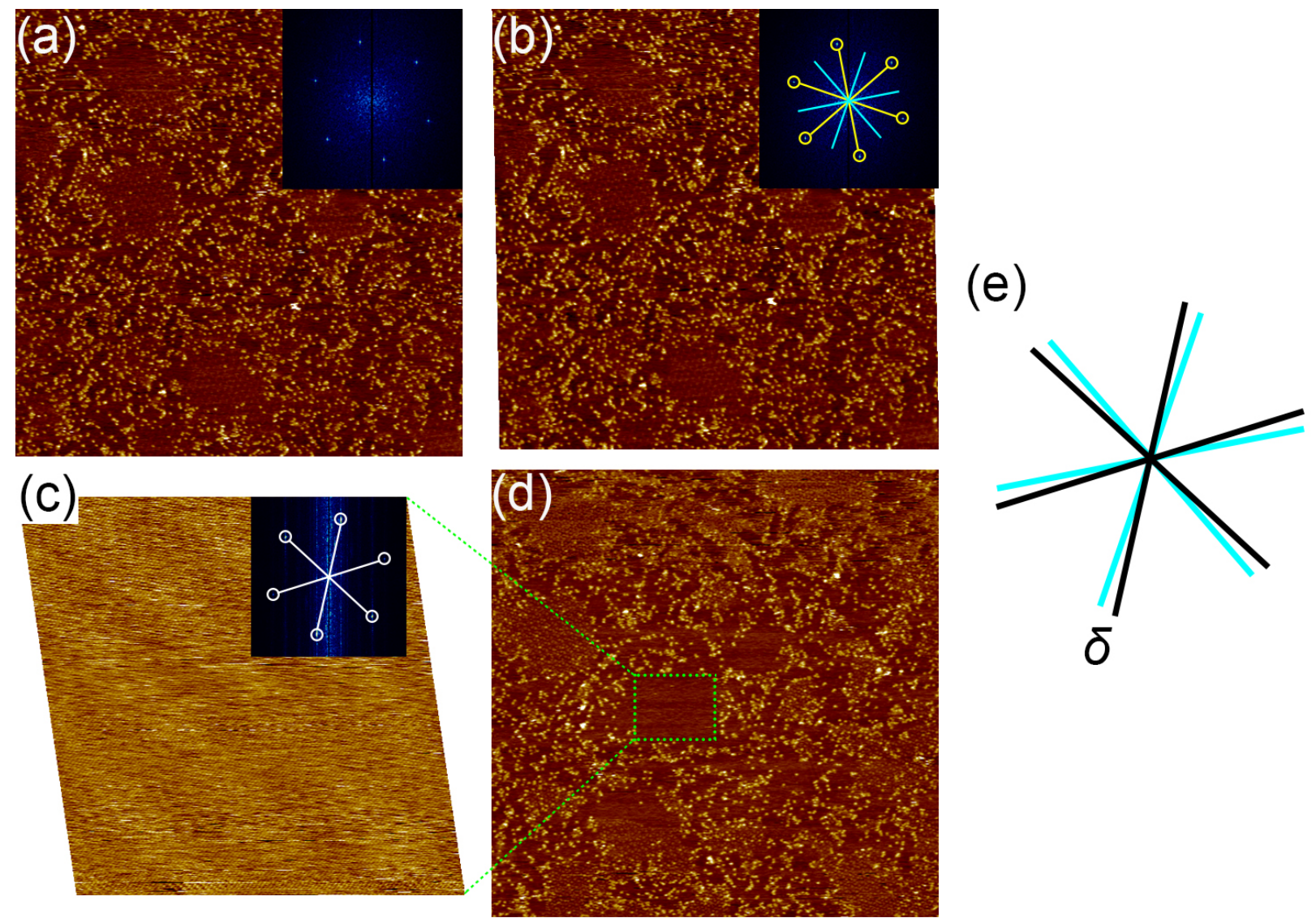

Figure S23. (a) STM image of the hexagonally functionalized graphite surface after DBA-OC6 templated grafting in 1-phenyloctane by $\mathrm{CV}\left(200 \mathrm{~nm} \times 200 \mathrm{~nm}, V_{\text {bias }}=-0.60 \mathrm{~V}, I_{\text {set }}=30 \mathrm{pA}\right)$. The inset corresponds to the 2D-FFT image. (b) Calibrated STM image of (a) using the unit cell parameters of DBA-OC6. In the inset, symmetry lines of the grafted pattern (axes $A$, see text) are marked in turquoise and lines connecting the center of and high-intensity spots of the 2D-FFT image are shown in yellow. (c) STM image of the graphite surface at the center of image (a) after lateral calibration $\left(25 \mathrm{~nm} \times 25 \mathrm{~nm}\right.$ before calibration, $\left.V_{\text {bias }}=-0.01 \mathrm{~V}, I_{\text {set }}=30 \mathrm{pA}\right)$. White lines in the inset correspond to the normals of the main symmetry axes of graphite. (d) Large area STM image of the hexagonally functionalized surface after imaging the graphite surface at the center $(200 \mathrm{~nm} \times 200 \mathrm{~nm}$, $V_{\text {bias }}=-0.60 \mathrm{~V}, I_{\text {set }}=30 \mathrm{pA}$ ). The area marked by the green dotted frame, lacking any grafted molecules, was created by the scanning of the STM tip at low bias voltages. ${ }^{5,6,7}$ (e) The axes $A$ 
(turquoise lines) are overlaid on the selected symmetry directions of the graphite lattice (black lines), defining the angle $\delta$. The angle $\delta$ measures $-6.5^{\circ}$.
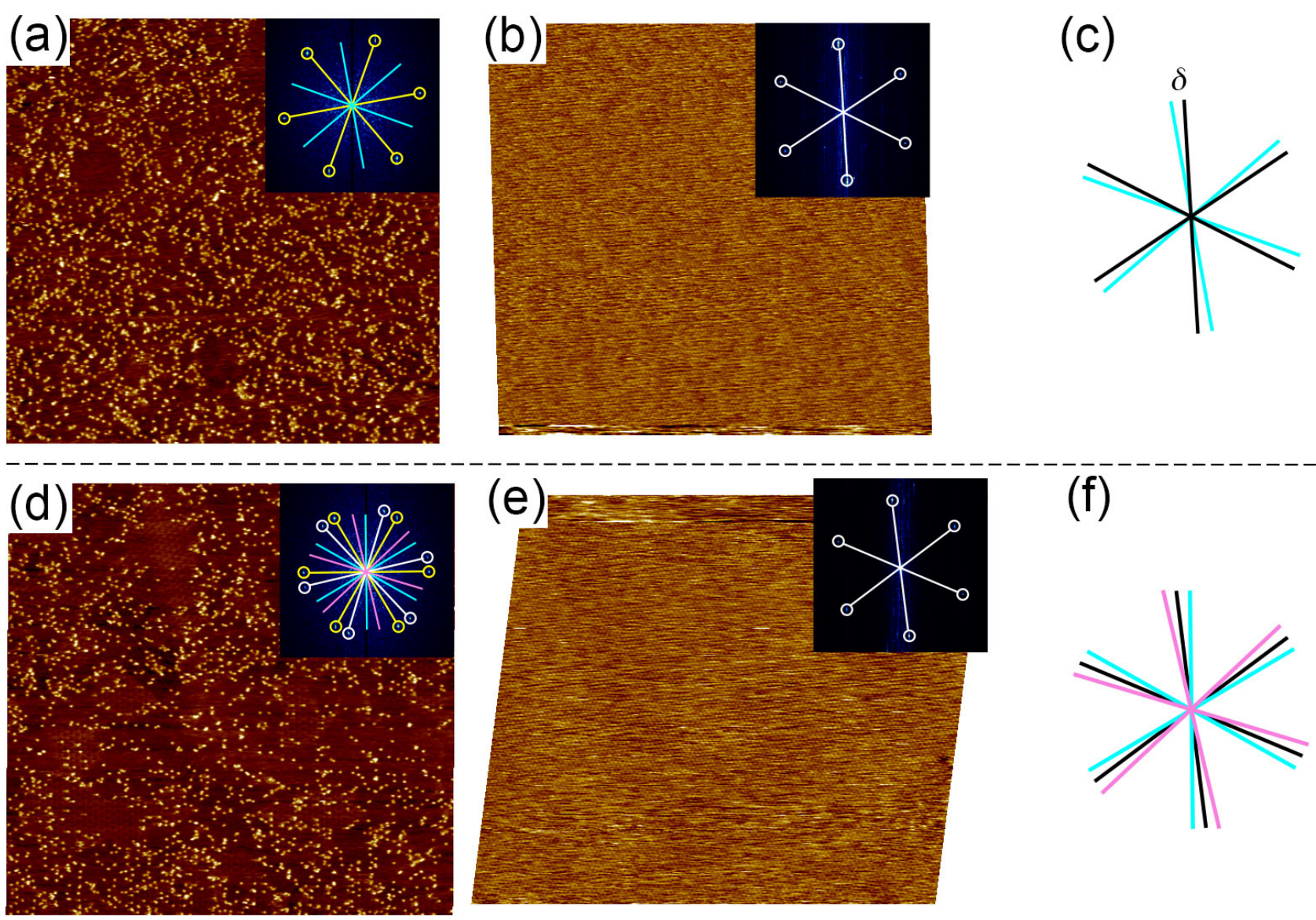

Figure S24. Two sets of chirality analyses for homochiral domain(s) (a-c) and for domains of both handedness (d-f). (a, d) Calibrated STM images of the hexagonally functionalized graphite surface after DBA-OC6 templated grafting in 1-phenyloctane by CA ((a) $V_{\text {bias }}=-0.60 \mathrm{~V}, I_{\text {set }}=30 \mathrm{pA}$, (d) $\left.V_{\text {bias }}=-0.60 \mathrm{~V}, I_{\text {set }}=30 \mathrm{pA}\right)$. The insets are the respective 2D-FFT images. Symmetry lines of the grafted pattern in (a) (axes $A$, defined above), are marked in turquoise. Lines connecting the center of and high-intensity spots of the 2D-FFT image are shown in yellow. Two sets of six bright spots in 2D-FFT of (d) indicate two different orientations of the hexagonal periodicities of the grafted aryl groups, and result therefore also in two sets of orientations of the symmetry lines (indicated in turquoise and pink lines). (b, e) Calibrated STM image of the corresponding underlying graphite surface $\left(25 \mathrm{~nm} \times 25 \mathrm{~nm}\right.$ before calibration, (b) $V_{\text {bias }}=-0.008 \mathrm{~V}, I_{\text {set }}=50 \mathrm{pA}$, and (e) $V_{\text {bias }}=-0.01 \mathrm{~V}$, $I_{\text {set }}=30 \mathrm{pA}$ ). White lines correspond to the normals of the main symmetry axes of graphite. (c, f) The axes $A$ (turquoise lines in (c) and (f), and turquoise and pink lines in (f) are overlaid on the selected symmetry directions of the graphite lattice (black lines), defining the angle $\delta$. (c) The angle $\delta$ is $+6.8^{\circ}$. (f) The angles $\delta$ are $+6.5^{\circ}$ and $-6.5^{\circ}$, indicating coexistence of both right- and left-handed arrangements. 

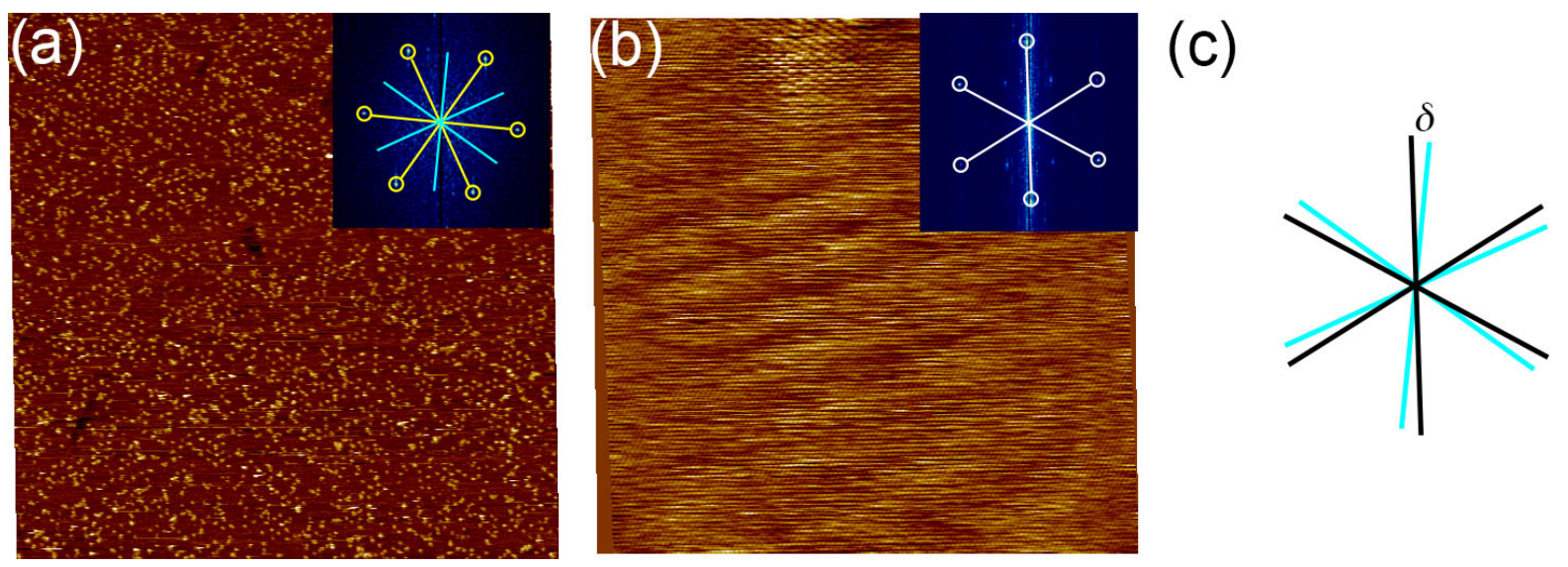

Figure S25. (a) Calibrated STM image of the functionalized graphite surface after cDBA-OC6(S)OC6 templated grafting in TCB by CV $\left(V_{\text {bias }}=-0.60 \mathrm{~V}, I_{\text {set }}=30 \mathrm{pA}\right)$. The inset is the corresponding 2D-FFT. Symmetry lines of the grafted pattern in (a, axes $A$, defined above), are marked in turquoise in the 2D-FFT. Lines connecting the center of and high-intensity spots of the 2D-FFT image are shown in yellow. (b) Calibrated STM image of the underlying graphite surface $(25 \mathrm{~nm} \times 25 \mathrm{~nm}$ before calibration, $V_{\text {bias }}=-0.01 \mathrm{~V}, I_{\text {set }}=30 \mathrm{pA}$ ). White lines correspond to the normals of the main symmetry axes of graphite. (c) The axes $A$ (turquoise lines) are overlaid on the selected symmetry directions of the graphite lattice (black lines). The angle $\delta$ is $-7.3^{\circ}$. 


\section{Synthesis of cDBA-OC6(S)-OC6}

General. All manipulations were performed under an argon atmosphere. All solvents were distilled or passed through activated alumina and copper catalyst in a Glass Contour solvent purification system prior use. All commercially available reagents were used as received. Tris(tertbutyldimethylsilyoxy)tris(methoxymethoxy)dehydrobenzo[12] annulene DBA-OTBS-OMOM was prepared following reported procedures. ${ }^{8}$

${ }^{1} \mathrm{H}(500 \mathrm{MHz})$ and ${ }^{13} \mathrm{C}(125 \mathrm{MHz}) \mathrm{NMR}$ spectra were measured on a JEOL ECA-500 spectrometer. For NMR measurements, chloroform- $d$ was used as the solvent, and the spectra were referenced to tetramethylsilane in the ${ }^{1} \mathrm{H}$ and ${ }^{13} \mathrm{C}$ NMR spectra $(0 \mathrm{ppm})$. Recycling GPC separation was undertaken with a JAI LC-5060 recycling chromatographs using $600 \mathrm{~mm} \times 20 \mathrm{~mm}$ JAIGEL$1 \mathrm{HR}$ and $2 \mathrm{HR}$ GPC columns with $\mathrm{CHCl}_{3}$ as the eluent. Other spectra were recorded by the use of the following instruments: Melting points (mp), Stuart Scientific SMP3; IR spectra, JASCO FT/IR-4100; mass spectra, JEOL JMS-T100GCV for FD ionization mode.

Scheme S1. Synthesis of cDBA-OC6(S)-OC6.
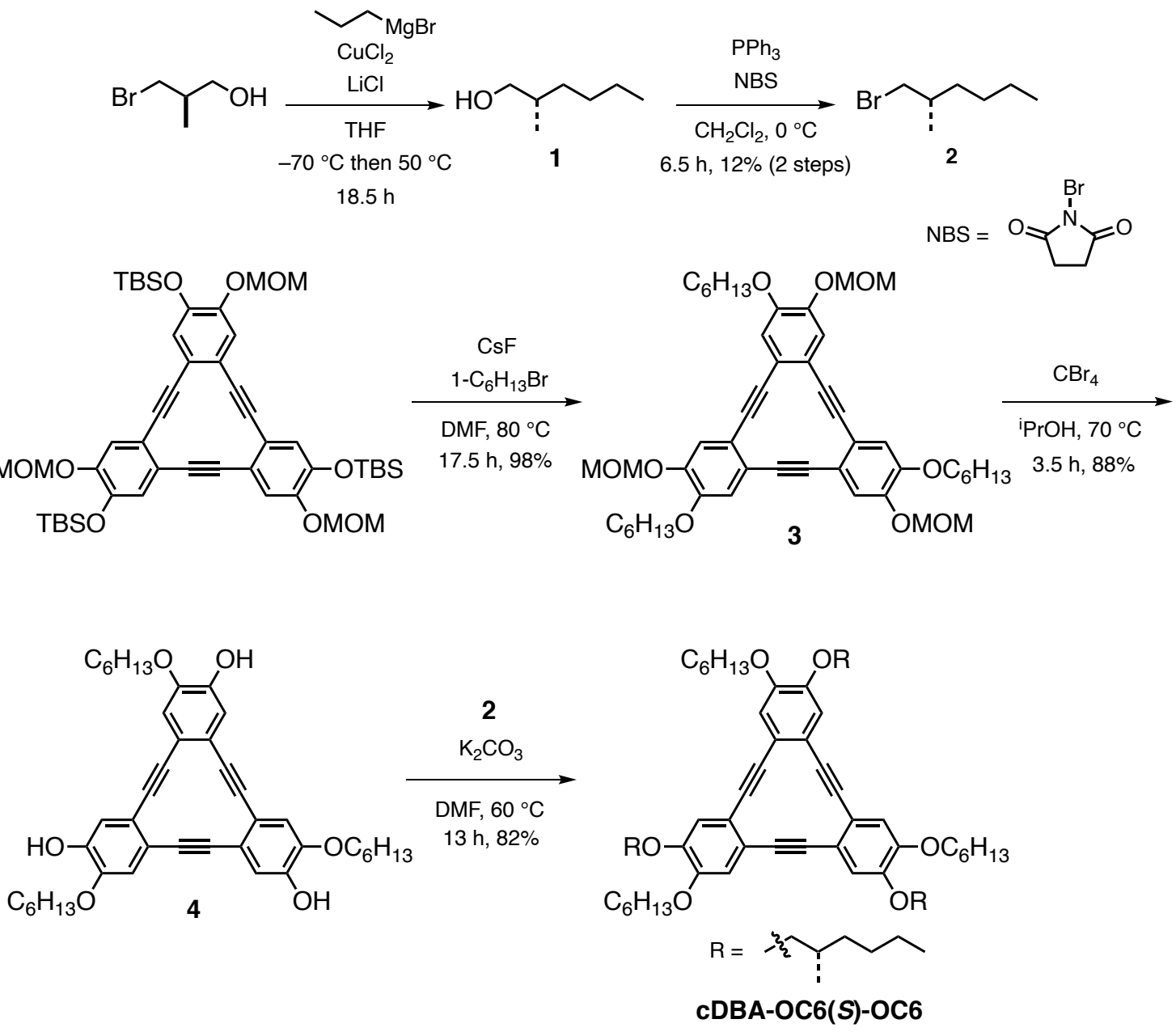
Synthesis of (S)-1-Bromo-2-methylhexane (2). To a suspension of magnesium (turnings, $962 \mathrm{mg}, 39.6 \mathrm{mg}$ atom) in THF (26 mL) in a two-necked round-bottom flask, 1-bromopropane (2.0 $\mathrm{mL}, 0.22 \mathrm{~mol}$ ) was added dropwise via a syringe. The mixture was stirred at $40{ }^{\circ} \mathrm{C}$ for $1.5 \mathrm{~h}$ and then cooled to room temperature. At the same time, $\mathrm{CuCl}_{2}$ (355 mg, $\left.2.64 \mathrm{mmol}\right), \mathrm{LiCl}(271 \mathrm{mg}, 6.39$ mmol) and THF ( $4 \mathrm{~mL})$ were added to another flask, and the mixture was stirred at $-70{ }^{\circ} \mathrm{C}$ for $2 \mathrm{~h}$. To this reaction vessel, the prepared Grignard reagent was transferred via a cannula. After subsequent addition of $(R)$-3-bromo-2-methyl-1-propanol (Sigma-Aldrich, 97\% purity, $340 \mu \mathrm{L}, 3.25 \mathrm{mmol}$ ), the mixture was stirred at $50{ }^{\circ} \mathrm{C}$ for 19 h. ${ }^{9}$ The reaction was quenched by the addition of an aqueous solution of ammonia (28 wt\%) and sat. $\mathrm{NH}_{4} \mathrm{Cl}$ aq. The products were extracted with $\mathrm{Et}_{2} \mathrm{O}$, and the organic phase was washed with water and brine and dried over $\mathrm{MgSO}_{4}$. After removal of the solvents under vacuum $\left(550 \mathrm{mbar}, 40{ }^{\circ} \mathrm{C}\right)$, the crude product mixture was subjected to a silica gel column chromatography (hexane/AcOEt $=5 / 1)$ to afford $(R)$-2-methylhexan-1-ol $(1,200 \mathrm{mg})$ together with impurities as a colorless oil. This oil was used for the next step without further purification.

A solution of $1(200 \mathrm{mg})$ in $\mathrm{CH}_{2} \mathrm{Cl}_{2}(12.4 \mathrm{~mL})$ was added to a Schlenk tube and cooled to $0{ }^{\circ} \mathrm{C}$. To this solution, $\mathrm{PPh}_{3}(1.11 \mathrm{~g}, 4.23 \mathrm{mmol})$ and $\mathrm{N}$-bromosuccinimide (NBS, $\left.743 \mathrm{mg}, 4.17 \mathrm{mmol}\right)$ were added. After stirring at room temperature for $7 \mathrm{~h}$, the solvents were removed under vacuum (700-800 mbar, $40{ }^{\circ} \mathrm{C}$ ). The crude product mixture was subjected to a silica gel column chromatography (hexane) to afford $(S)$-1-bromo-2-methylhexane (2, $67.2 \mathrm{mg}, 12 \%$ yield in two steps) as a colorless oil. All spectra of $\mathbf{2}$ agreed with those in a previous report. ${ }^{10}$

Synthesis of 3. DBA-OTBS-OMOM $(20.1 \mathrm{mg}, 23.1 \mu \mathrm{mol})$ was added to a Schlenk tube. DMF $(1.0 \mathrm{~mL})$ and $\mathrm{CsF}(32.5 \mathrm{mg}, 214 \mu \mathrm{mol})$ were added. To the resulting suspension, 1bromohexane $(32.5 \mu \mathrm{L}, 232 \mu \mathrm{mol})$ was added via a syringe. After stirring at $80{ }^{\circ} \mathrm{C}$ for $17.5 \mathrm{~h}$, the solvent was removed under vacuum. The residue was subjected to a silica gel column chromatography (hexane/ $\mathrm{CH}_{2} \mathrm{Cl}_{2}$, from $1 / 0$ to $\left.1 / 2\right)$ to furnish $3(17.6 \mathrm{mg}, 98 \%)$ as yellow solid. $\mathrm{mp}$ 122.3-122.6 ${ }^{\circ} \mathrm{C} ;{ }^{1} \mathrm{H} \mathrm{NMR}\left(\mathrm{CDCl}_{3}, 500 \mathrm{MHz}, 17.2{ }^{\circ} \mathrm{C}\right) \delta 7.03(\mathrm{~s}, 3 \mathrm{H}), 6.77(\mathrm{~s}, 3 \mathrm{H}), 5.20(\mathrm{~s}, 6 \mathrm{H}), 4.00$ (t, $J=6.8,6 \mathrm{H}$ ), 3.53 (s, 9H), 1.83 (quint, $J=7.0 \mathrm{~Hz}, 6 \mathrm{H}$ ), 1.45 (quint, $J=6.8 \mathrm{~Hz}, 6 \mathrm{H}$ ), $1.38-1.29$ (m, 12H), $0.91(\mathrm{t}, J=6.0 \mathrm{~Hz}, 9 \mathrm{H}) ;{ }^{13} \mathrm{C} \mathrm{NMR}\left(\mathrm{CDCl}_{3}, 125 \mathrm{MHz}, 25.0{ }^{\circ} \mathrm{C}\right) \delta 149.5,146.8,121.6,119.4$, 119.3, 115.7, 95.4, 92.0, 91.6, 69.0, 56.4, 31.5, 29.0, 25.6, 22.6, 14.0; IR (KBr) 2952, 2869, 2828, 2213, 1595, 1513, 1473, 1389, 1347, 1262, 1227, 1191, 1152, 1081, 1062, 979, 926, $862 \mathrm{~cm}^{-1}$; HRMS (FD): $m / z$ calcd for $\mathrm{C}_{48} \mathrm{H}_{60} \mathrm{O}_{9}\left(\mathrm{M}^{+}\right)$780.4237, Found: 780.4231 .

Synthesis of 4. Compound $3(32.2 \mathrm{mg}, 41.2 \mu \mathrm{mol})$ was added to a Schlenk tube. To a Schlenk tube, $\mathrm{CBr}_{4}(50.2 \mathrm{mg}, 151 \mu \mathrm{mol})$ and ${ }^{i} \mathrm{PrOH}(0.5 \mathrm{~mL})$ were added. After stirring at $70{ }^{\circ} \mathrm{C}$ for $3.5 \mathrm{~h}$, the solvent was removed under vacuum. Purification by a silica gel column chromatography (hexane $/ \mathrm{CH}_{2} \mathrm{Cl}_{2}$, from $1 / 0$ to $\left.1 / 1\right)$ gave $4\left(24.5 \mathrm{mg}, 88 \%\right.$ ) as yellow solid. mp $169.0-170.5{ }^{\circ} \mathrm{C}$; ${ }^{1} \mathrm{H}$ $\operatorname{NMR}\left(\mathrm{CDCl}_{3}, 500 \mathrm{MHz}, 25.0^{\circ} \mathrm{C}\right) \delta 6.79(\mathrm{~s}, 3 \mathrm{H}), 6.73(\mathrm{~s}, 3 \mathrm{H}), 5.65(\mathrm{~s}, 3 \mathrm{H}), 4.03(\mathrm{t}, J=6.8 \mathrm{~Hz}, 6 \mathrm{H})$, 
1.81 (quint, $J=7.1 \mathrm{~Hz}, 6 \mathrm{H}), 1.45$ (quint, $J=7.5 \mathrm{~Hz}, 6 \mathrm{H}), 1.39-1.30(\mathrm{~m}, 12 \mathrm{H}), 0.92(\mathrm{t}, J=7.3 \mathrm{~Hz}$, $9 \mathrm{H}) ;{ }^{13} \mathrm{C} \mathrm{NMR}\left(\mathrm{CDCl}_{3}, 125 \mathrm{MHz}, 18.5{ }^{\circ} \mathrm{C}\right) \delta 146.0,145.9,120.2,119.2,117.1,114.3,91.8,91.2$, 69.1, 31.5, 29.0, 25.6, 22.6, 14.0; IR (KBr) 3531, 3413, 2953, 2931, 2858, 2209, 1605, 1560, 1508, 1473, 1365, 1299, 1253, 1210, 1193, 1065, 1019, 990, $873 \mathrm{~cm}^{-1}$; HRMS (FD): $m / z$ calcd for $\mathrm{C}_{42} \mathrm{H}_{48} \mathrm{O}_{6}$ $\left(\mathrm{M}^{+}\right)$648.3451, Found: 648.3451.

Synthesis of cDBA-OC6(S)-OC6. Compound 4 (18.9 mg, 29.1 $\mu \mathrm{mol})$, DMF (0.70 mL), $\mathrm{K}_{2} \mathrm{CO}_{3}(29.0 \mathrm{mg}, 210 \mu \mathrm{mol})$ and $(S)$-1-bromo-2-methylhexane $2(31.7 \mathrm{mg}, 177 \mu \mathrm{mol})$ were added to a Schlenk tube. After stirring at $60{ }^{\circ} \mathrm{C}$ for $17 \mathrm{~h}$, the solvent was removed under vacuum. The residue was subjected to a silica gel column chromatography (hexane $/ \mathrm{CH}_{2} \mathrm{Cl}_{2}$, from $1 / 0$ to $1 / 1$ ) followed by recycling GPC and recrystallization from $\mathrm{CH}_{2} \mathrm{Cl}_{2} /$ methanol to give cDBA-OC6(S)-OC6 (5.6 mg, $25 \%)$ as yellow solid. mp 96.2-97.0 ${ }^{\circ} \mathrm{C} ;{ }^{1} \mathrm{H} \mathrm{NMR}\left(\mathrm{CDCl}_{3}, 500 \mathrm{MHz}, 24.7{ }^{\circ} \mathrm{C}\right) \delta 6.71(\mathrm{~s}, 6 \mathrm{H}), 3.95(\mathrm{t}$, $J=6.5 \mathrm{~Hz}, 6 \mathrm{H}), 3.81(\mathrm{dd}, J=9.5,6.5 \mathrm{~Hz}, 3 \mathrm{H}), 3.71(\mathrm{dd}, J=9.0,7.0 \mathrm{~Hz}, 3 \mathrm{H}), 2.00-1.93(\mathrm{~m}, 3 \mathrm{H})$, 1.79 (quint, $J=7.1 \mathrm{~Hz}, 6 \mathrm{H}), 1.50-1.18(\mathrm{~m}, 36 \mathrm{H}), 1.02(\mathrm{~d}, J=7 \mathrm{~Hz}, 9 \mathrm{H}), 0.92-0.90(\mathrm{~m}, 18 \mathrm{H}) ;{ }^{13} \mathrm{C}$ $\mathrm{NMR}\left(\mathrm{CDCl}_{3}, 125 \mathrm{MHz}, 25.0^{\circ} \mathrm{C}\right) \delta 149.3,149.2,119.72,119.67,115.7,91.9,91.8,74.2,69.0,33.2$, 33.1, 31.6, 29.15, 29.11, 25.7, 22.9, 22.6, 17.0, 14.1, 14.0; IR (KBr) 3087, 2954, 2926, 2870, 2210, 1699, 1592, 1531, 1512, 1470, 1353, 1271, 1233, 1071, 1096, 1026, 987, 937, 886, 856, $732 \mathrm{~cm}^{-1}$; HRMS (FD): $m / z$ calcd for $\mathrm{C}_{63} \mathrm{H}_{90} \mathrm{O}_{6}\left(\mathrm{M}^{+}\right)$942.6737, Found: 942.6772. 
14. ${ }^{1} \mathrm{H}$ and ${ }^{13} \mathrm{C}$ NMR Spectra of New Compounds.
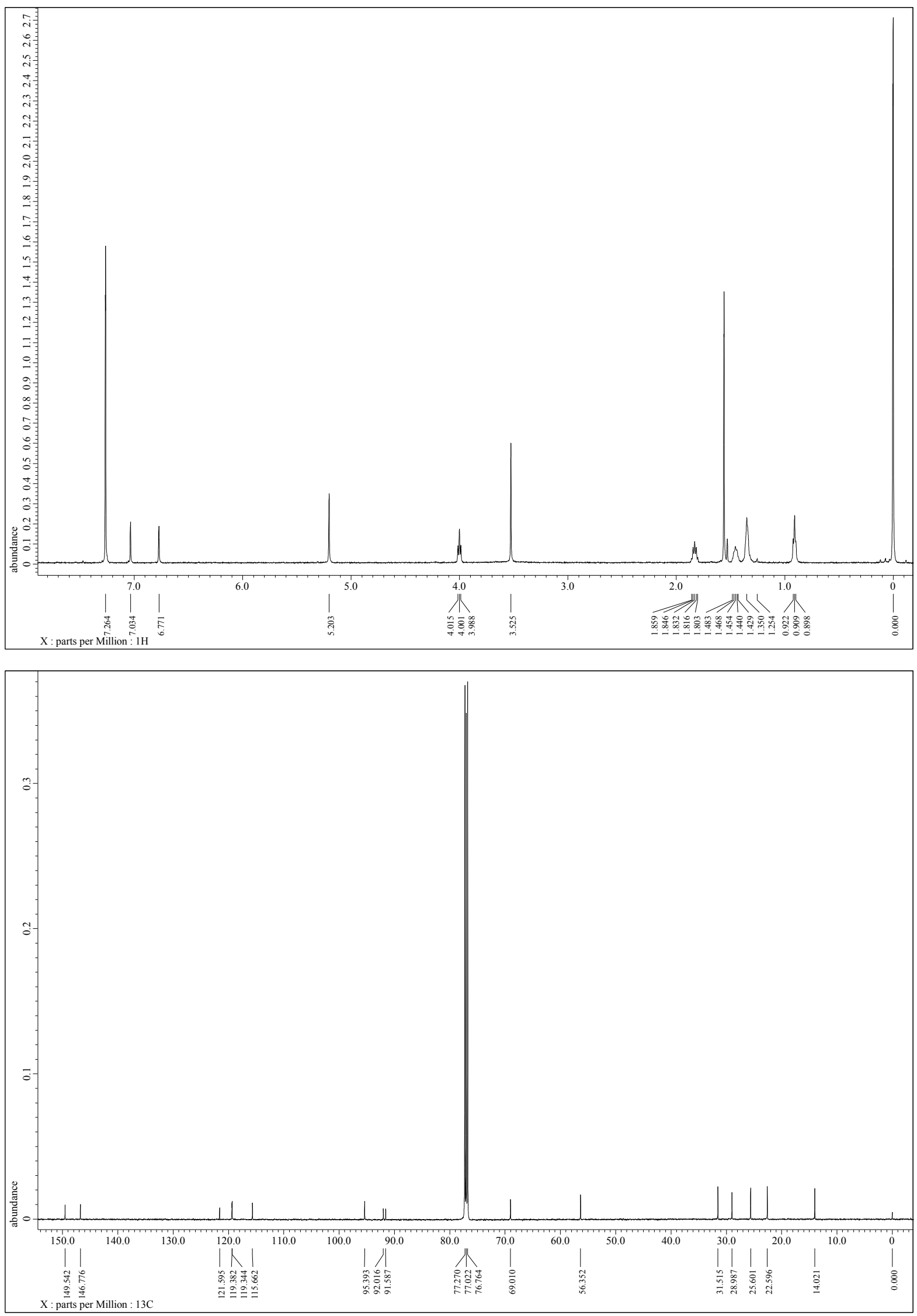

Figure S26. ${ }^{1} \mathrm{H}$ (top) and ${ }^{13} \mathrm{C}$ (bottom) NMR spectra of 3 in $\mathrm{CDCl}_{3}$. 

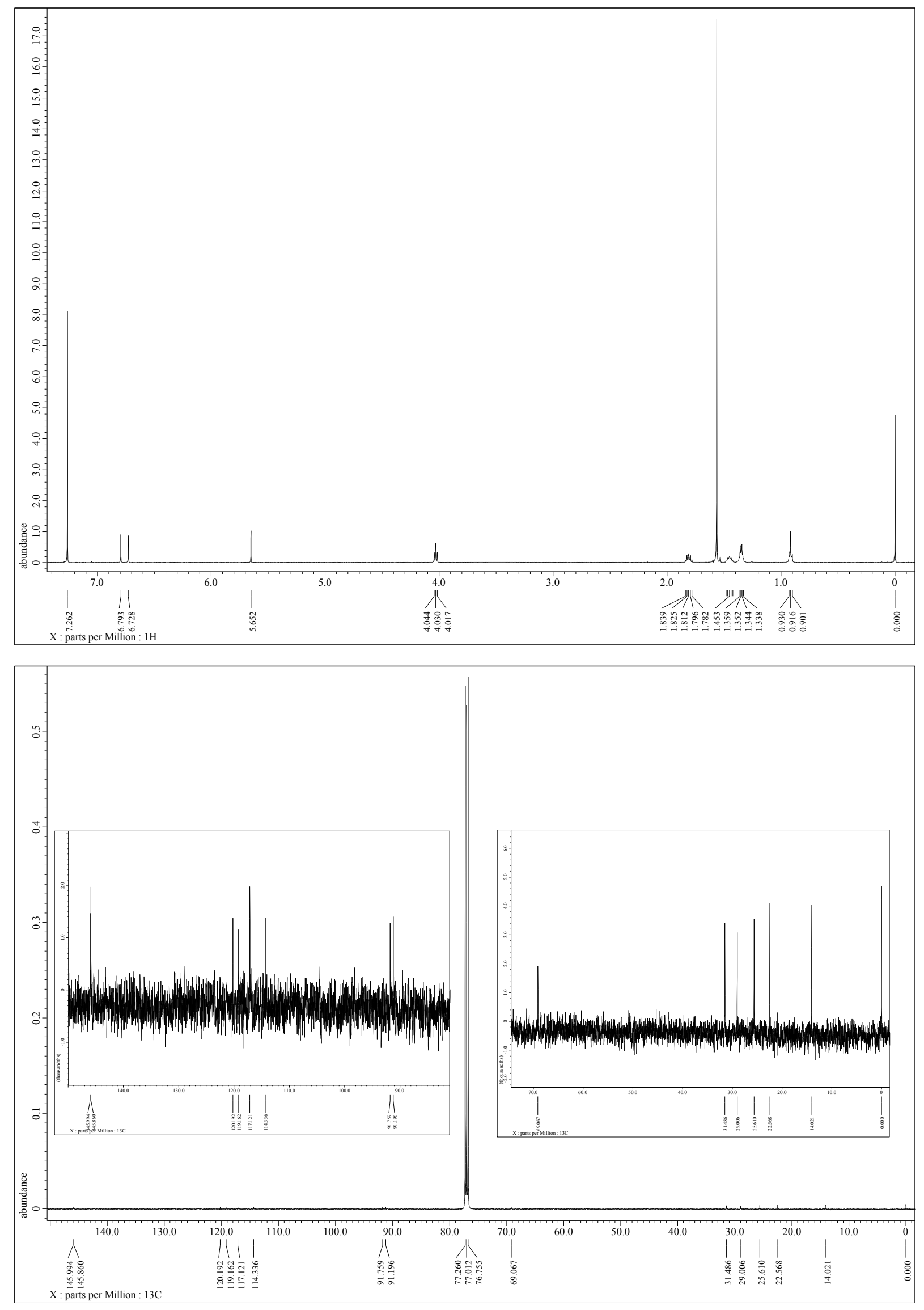

Figure S27. ${ }^{1} \mathrm{H}$ (top) and ${ }^{13} \mathrm{C}$ (bottom) NMR spectra of 4 in $\mathrm{CDCl}_{3}$. 

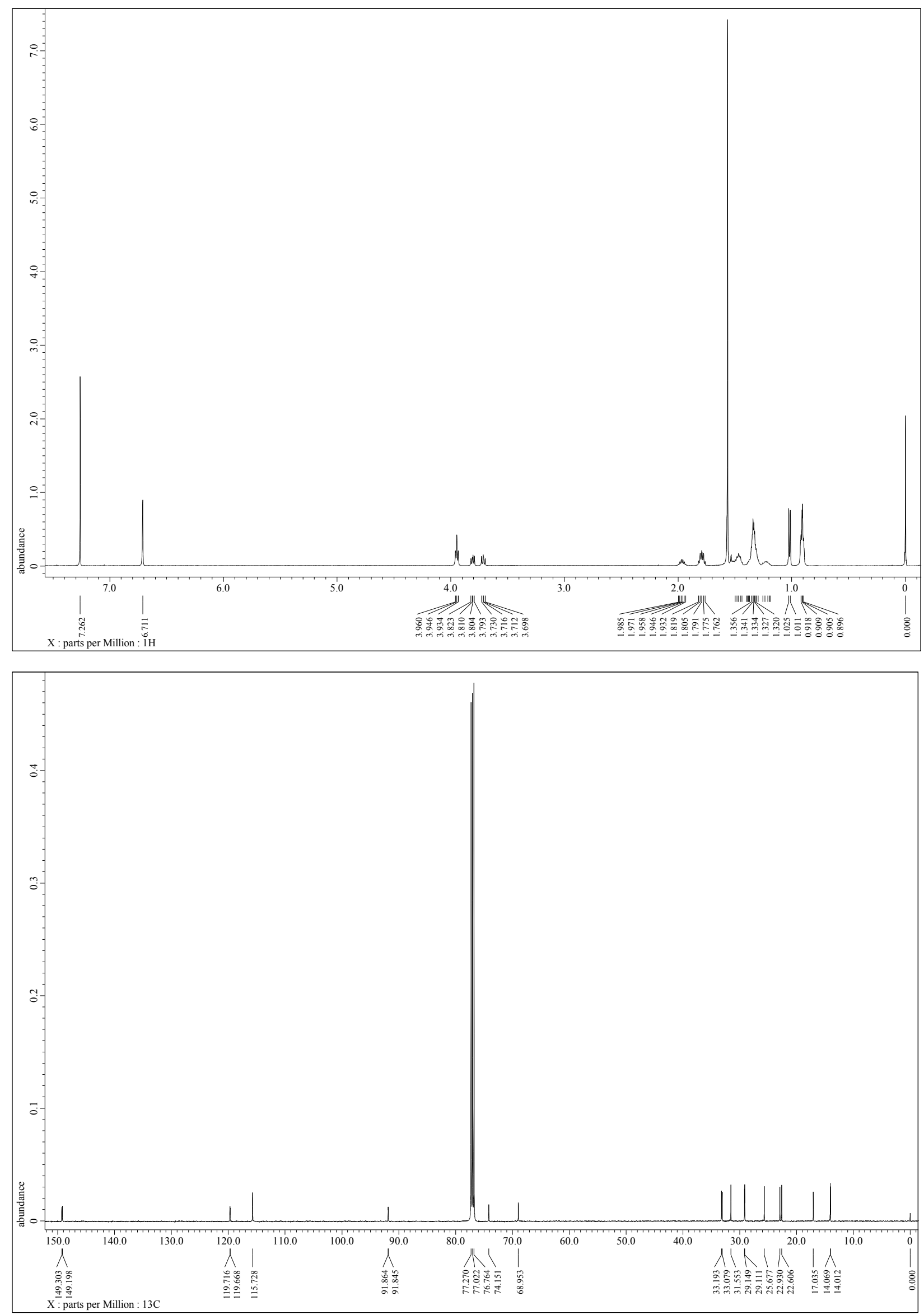

Figure S28. ${ }^{1} \mathrm{H}$ (top) and ${ }^{13} \mathrm{C}$ (bottom) NMR spectra of cDBA-OC6(S)-OC6 in $\mathrm{CDCl}_{3}$. 


\section{References}

(1) Destoop, I.; Ghijsens, E.; Katayama, K.; Tahara, K.; Mali, K. S.; Tobe, Y.; De Feyter, S. SolventInduced Homochirality in Surface-Confined Low-Density Nanoporous Molecular Networks. J. Am. Chem. Soc. 2012, 134, 19568-19571.

(2) Balandina, T.; Tahara, K.; Sändig, N.; Blunt, M. O.; Adisoejoso, J.; Lei, S.; Zerbetto, F.; Tobe. Y.; De Feyter, S. Role of Substrate in Directing the Self-Assembly of Multicomponent Supramolecular Networks at the Liquid-Solid Interface. ACS Nano 2012, 6, 8381-8389.

(3) Kim, J.-H.; Tahara, K.; Jung, J.; De Feyter, S.; Tobe, Y.; Kim, Y.; Kawai, M. Ordering of Molecules with $\pi$-Conjugated Triangular Core by Switching Hydrogen Bonding and van der Waals Interactions. J. Phys. Chem. C 2012, 116, 17082-17088.

(4) Tahara, K.; Ishikawa, T.; Hirsch, B. E.; Kubo, Y.; Brown, A.; Eyley, S.; Daukiya, L.; Thielemans, W.; Li, Z.; Walke, P.; Hirose, S.; Hashimoto, S.; De Feyter, S.; Tobe, Y. Self-Assembled Monolayer as Templates for Linearly Nanopatterned Covalent Chemical Functionalization of Graphite and Graphene Surfaces. ACS Nano 2018, 12, 11520-11528.

(5) Greenwood, J.; Phan, T. H.; Fujita, Y.; Li, Z.; Ivasenko, O.; Vanderlinden, W.; Van Gorp, H.; Frederickx, W.: Lu, G.; Tahara, K.; Tobe, Y.; Uji-i, H.; Mertens, S. F. L.; De Feyter, S. Covalent Modification of Graphene and Graphite Using Diazonium Chemistry: Tunable Grafting and Nanomanipulation. ACS Nano 2015, 9, 5520-5535.

(6) Hossain, M. Z.; Walsh, M. A.; Hersam, M. C. Scanning Tunneling Microscopy, Spectroscopy, and Nanolithography of Epitaxial Graphene Chemically Modified with Aryl Moieties. J. Am. Chem. Soc. 2010, 132, 15399-15403.

(7) Bragança, A. M.; Hirsch, B. E.; Sanz-Matias, A.; Hu, Y.; Walke, P.; Tahara, K.; Harvey, J. N.; Tobe, Y.; De Feyter, S. How Does Chemisorption Impact Physisorption? Molecular View of Defect Incorporation and Perturbation of Two-Dimensional Self-Assembly. J. Phys. Chem. C 2018, 122, 24046-24054.

(8) Tahara, K.; Yamaga, H.; Ghijsens, E.; Inukai, K.; Adisoejoso, J.; Blunt, M. O.; De Feyter, S.; Tobe, Y. Control and Induction of Surface-Confined Homochiral Porous Molecular Networks. Nat. Chem. 2011, 3, 714-719.

(9) Schlamp, K. K.; Gries, R.; Khaskin, G.; Brown, K.; Khaskin, E.; Judd, G. J. R.; Gries, G. Pheromone Components from Body Scales of Female Anarsia Lineatella Induce Contacts by Conspecific Males. J. Chem. Ecol. 2005, 31, 2897-2911.

(10) Tamagawa, H.; Takikawa, H.; Mori, K. Synthesis of All the Stereoisomers of 10,14Dimethyloctadec-1-Ene, 5,9-Dimethyloctadecane and 5,9-Dimethylheptadecane, the Sex Pheromone Components of the Apple Leafminer. Lyonetia prunifoliella. Eur. J. Org. Chem. 1999, 973-978. 